Aus der Abteilung Anatomie und Zellbiologie

(Komm. Leiter: Prof. Dr. rer. nat. J. Wilting)

im Zentrum Anatomie

der Medizinischen Fakultät der Universität Göttingen

\title{
Immunhistologische Charakterisierung experimenteller Lymphangiome der Maus
}

\author{
INAUGURAL - DISSERTATION \\ zur Erlangung des Doktorgrades \\ der Medizinischen Fakultät der \\ Georg-August-Universität zu Göttingen
}

vorgelegt von

Gerrit Sebastian Schnöink

aus

Bremen

Göttingen 2009 
Dekan: Prof. Dr. med. C. Frömmel

I. Berichterstatter: Prof. Dr. rer. nat. J. Wilting

II. Berichterstatter/in:

III. Berichterstatter/in:

Tag der mündlichen Prüfung: 


\section{Inhaltsverzeichnis}

1. Einleitung 1

1.1 Das Lymphangiom beim Menschen 1

1.2 Induktion von Lymphangiomen im Tiermodell 2

1.3 Immunhistologische Untersuchungen von Mauslymphangiomen 3

2. Material und Methoden $\quad 5$

2.1 Experimentelle Lymphangiome 5

2.2 Fixierung und Einbettung der Präparate 5

2.3 Herstellung der Gefrierschnitte 5

$2.4 \quad$ Herstellung der Paraffinschnitte 6

2.5 Immunfluoreszenz-Färbung 6

2.6 Verwendete Antikörper 6

2.7 HE-Färbung nach Mayer $\quad 7$

2.8 Verwendete Lösungen 8

2.9 Verwendete Materialien und Geräte 9

3. Ergebnisse 11

3.1 Makroskopische und mikroskopische Aspekte der Lymphangiome $\quad 11$

3.2 Immunfluoreszenzfärbungen mit anti-CD45- und anti-Lyve1-Antikörpern 12

3.3 Immunfluoreszenzfärbungen mit anti-Prox1-, anti-Lyve1- und anti-CD31-Antikörpern 14

3.4 Immunfluoreszenzfärbungen mit anti-Podoplanin- und $\begin{array}{ll}\text { anti-Lyve1-Antikörpern } & 17\end{array}$

3.5 Immunfluoreszenzfärbungen mit anti-Meca32-, anti-VEGFR-2- und anti-Lyve1-Antikörpern 18

3.6 Immunfluoreszenzfärbungen mit anti-alpha-SMA- und anti-CD31-Antikörpern 21

4. Diskussion 23

$\begin{array}{lll}4.1 & \text { Fragestellung } & 23\end{array}$

4.2 Immunhistologische Untersuchung der Endothelzellen des Lymphangioms $\quad 24$ 
4.3 Das experimentelle Lymphangiom der Maus nach Mancardi et al. (1999) 25

$\begin{array}{lll}4.4 & \text { Freund's incomplete adjuvant (FIA) } & 27\end{array}$

4.5 Subkutane Injektionen von FIA und Mineralölen bei Mäusen 27

4.6 Intraperitoneale Injektionen von FIA und Mineralölen bei Mäusen 28

4.7 Phagozytäre Reaktionen nach intraperitonealer Öl-Injektion 30

4.8 Das inflammatorische Geschehen und seine Bedeutung für die Hämund Lymphangiogenese 31

4.9 Rolle der VEGF-Rezeptoren bei der Häm- und Lymphangiogenese 32

4.10 Einfluss der Blutendothelzellen auf die Lymphangiogenese 33

4.11 Hypothese über die Genese der Öl-Granulome 34

4.12 Bewertung der Übertragbarkeit des Tiermodells auf den Menschen 35

5. Zusammenfassung 37

6. Literaturverzeichnis $\quad 38$

7. Abkürzungsverzeichnis 47 


\section{Einleitung}

\subsection{Das Lymphangiom beim Menschen}

Das menschliche Lymphangiom stellt ca. 5\% aller benignen Tumoren des Säuglings- und Kindesalters dar (Bill und Sumner 1965; Zadvinskis et al. 1992; Charabi et al. 2000). Dabei manifestiert sich die Erkrankung in 50-60\% der Fälle bereits direkt nach der Geburt, meistens als eine asymptomatische weiche, halb-solide Masse, die zu infiltrativem Wachstum fähig ist, jedoch keine Tendenz zur malignen Entartung zeigt. Insgesamt können 80-90\% der Läsionen bis zum 2. Lebensjahr diagnostiziert werden (Bill und Sumner 1965; Zadvinskis et al. 1992). Lymphangiome können sowohl solitär oder auch als multiple flüssigkeitsgefüllte Hohlräume imponieren und sind am häufigsten im Bereich des Nackens lokalisiert (Goetsch 1938; Potter EL und Craig 1975; Hamoir et al. 2001; Giguere et al. 2002a). Insgesamt ist ihr Erscheinungsbild beim Menschen jedoch vielgestaltig. Die Klassifikation von Landing und Faber (1956) teilt die Lymphangiome daher in drei Gruppen ein. Aus dünnwandigen lymphatischen Kanälen mit kapillärem Durchmesser aufgebaute Läsionen werden als Lymphangioma simplex bezeichnet, während aus dilatierten lymphatischen Kanälen bestehende Läsionen, die häufig von einer fibrösen Tunica adventitia umgeben sind, von ihnen als kavernöse Lymphangiome klassifiziert werden. Des Weiteren differenzieren sie das zystische Lymphangiom oder zystische Hygrom, das aus Zysten von einigen Millimetern bis hin zu mehreren Zentimetern im Durchmesser aufgebaut ist.

Von einigen Autoren wird die Ursache für die Entstehung der Lymphangiome beim Menschen in der fehlenden Dränage von Lymphe aus den (primordialen) Lymphsäcken des Embryos in das venöse System angesehen. Sekundär kommt es so zu einer Vergrößerung von obliterierten lymphatischen Kanälen, aus denen sich Zysten entwickeln können (Smith 1982; Giguere et al. 2002a; Koch BL 2005; Lee BB et al. 2005). Andere Autoren gehen von einer abnormalen Abkapselung der (primordialen) Lymphsäcke in der frühen Embryogenese als Ursache aus (Goetsch 1938; Philips und McGahan 1981). Eine weitere Theorie macht den Verlust der Verbindung von aussprossenden Lymphgefäßanlagen zur lymphatischen Anlage der Lymphsäcke für die Entstehung der mit Lymphe gefüllten Zysten verantwortlich (Lee K und Klein 1980).

Als Therapieoptionen steht neben der chirurgischen Intervention auch die Sklerotherapie zur Verfügung, wobei die chirurgische Intervention zu Zeit der empfohlene Therapiestandard ist (Fageeh et al. 1997; Alqahtani et al. 1999; Orvidas und Kasperbauer 2000). Aufgrund der Nähe 
von Lymphbahnen zu vitalen Nerven und Blutgefäßen ist eine komplette chirurgische Exzision jedoch kaum möglich. Die Rezidivrate beträgt dadurch zum Teil über 50\%, auch liegen Berichte von komplikativen Verläufen unter anderem mit Paralysen vor (Charabi et al. 2000). Die Sklerotherapie von Lymphangiomen, zum Beispiel durch Injektion von Picibanil (OK-432), einem Derivat niedrig virulenter mit Benzylpenicillin inkubierter Staphylococcus-pyogenes-Stämme, bei der es zur Sklerosierung lymphatischer Gefäße kommt, zeigt eine $>60 \%$ ige Reduktion des Volumens der behandelten Lymphangiome in $86 \%$ der Fälle (Giguere et al. 2002b). Vor allem bei der perkutanen Behandlung makrozystischer Läsionen ist die Sklerotherapie, aufgrund des reduzierten Risikos von Komplikationen, das bevorzugte Therapieverfahren (Ogita et al. 1994; Greinwald et al. 1999).

Sowohl um die bestehenden Therapieverfahren zu verbessern, beispielsweise um neue Substanzen für die Sklerotherapie zu testen, als auch zur Erforschung neuer möglicherweise kausaler Therapien, ist ein Tiermodell für die Lymphangiomforschung unverzichtbar. Zusätzlich bietet ein Tiermodell die Möglichkeit, Lymphendothelzellen zu isolieren und die an der Lymphangiogenese beteiligten Faktoren zu untersuchen. Ein Maus-Lymphangiom-Modell wurde 1999 von Mancardi et al. vorgestellt. In meiner Arbeit habe ich nach Mancardi et al. (1999) experimentell, durch intraperitoneale Injektion von Freund's incomplete adjuvant (FIA), in Mäusen erzeugte Lymphangiome mit Hilfe verschiedener Antikörper untersucht und immunhistologisch charakterisiert.

\subsection{Induktion von Lymphangiomen im Tiermodell}

Vor einigen Jahren beschrieben Mancardi et al. (1999) ein Modell zur Induktion experimenteller Lymphangiome bei Mäusen, welches inzwischen zu einem etablierten Verfahren bei der Gewinnung neuer monoklonaler Antikörper gegen Lymphendothelzellen (Ezaki et al. 2006) und auch zur Isolierung lymphendothelialer Zelllinien geworden ist (Sironi et al. 2006). Ezaki et al. (2004) zeigten, dass sich, wie von Mancardi et al. (1999) beschrieben, durch intraperitoneale Injektionen von Freund's Incomplete Adjuvant (FIA) auch bei Ratten experimentelle Lymphangiome induzieren lassen. FIA besteht im Wesentlichen aus Mineralöl und es muss angemerkt werden, dass das Verfahren intraperitonealer Öl-Injektionen in den 60er Jahren durch eine Reihe von Forschern auf der Suche nach einem geeigneten Tiermodell für Plasmazelltumore schon einmal beschrieben worden war. Die histologischen Untersuchungen der intraperitonealen Läsionen zeigten, dass es sich um komplexe Tumore aus Endothelzellen und Zellen des 
Immunsystems handelte und dass mit der Phagozytose des Fremdmaterials befasste Makrophagen einen erheblichen Anteil an der Zellmasse hatten (Potter M und Robertson 1960; Potter M und Boyce 1962; Potter M und MacCardle 1964; Takakura et al. 1966). In ihrer Arbeit bezeichnen Potter M und MacCardle (1964) die von ihnen induzierten Läsionen daher als ÖlGranulome. Pullinger und Florey beobachteten bereits 1937, dass subkutane Injektionen von Fremdmaterial zu chronisch inflammatorischen Reaktionen des umliegenden Gewebes führten und dass sich auf diese Weise Lymphangiogenese auslösen ließ. Eine deutliche Vermehrung von Lymphgefäßen wurde auch von Dale (1961) beobachtet, nachdem sie FIA subkutan in Mäuseohren injiziert hatte. Entsprechend den Möglichkeiten ihrer Zeit gründen die Beschreibungen der experimentellen Lymphangiome und der durch Mineralöle induzierten Lymphgefäßproliferation in erster Linie auf lichtmikroskopischen Untersuchungen oder auf Tuscheinjektionen. Eine Untersuchung mit spezifischen Immunfluoreszensmarkern für Lymphendothel, sowie weiteren Pan-Endothelzell und Pan-Leukozytenmarkern ist bisher an Balb/c-Mäusen nicht durchgeführt worden. Das Modell der experimentellen Lymphangiome nach Mancardi et al. (1999), das sich bereits als nützliches Verfahren bei der Gewinnung großer Mengen von Lymphendothelzellen erwiesen hat, wird sowohl von Short et al. (2007) als auch von Mancardi et al. (1999) in ihren Arbeiten als geeignetes Instrument angesehen, um Therapiekonzepte zur Behandlung lymphatischer Malformationen des Menschen zu entwickeln. Der chronisch inflammatorische Aspekt des FIA, der vor allem von den Forschern in den 60er Jahren beschrieben wurde, bleibt hier jedoch weitgehend unbeachtet, weshalb ich in meiner Arbeit sowohl die durch das FIA induzierte Gefäßproliferation als auch die inflammatorische Reaktion des Peritoneums auf das FIA untersucht habe.

\subsection{Immunhistologische Untersuchungen von Mauslymphangiomen}

In meiner Arbeit habe ich die nach der Methode von Mancardi et al. (1999) induzierten experimentellen Lymphangiome mit Hilfe verschiedener Antikörper untersucht, wobei die Lymphendothelmarker Prox1 (Wigle und Oliver 1999; Rodriguez-Niedenführ et al. 2001; Wigle et al. 2002; Hong et al. 2002), Lyve1 (Banerji et al. 1999; Skobe und Detmar 2000; Jackson et al. 2001; Prevo et al. 2001) und Podoplanin (Wetterwald et al. 1996; Kriehuber et al. 2001; Petrova et al. 2002; Hirakawa et al. 2003; Schacht et al. 2003) zur Charakterisierung der Lymphgefäße 
eingesetzt wurden. Meca32 (Engelhardt et al. 1994) und VEGFR-2 (Kriehuber et al. 2001; Nagy et al. 2002; Makinen et al. 2001a) erwiesen sich als Marker für Blutendothelzellen innerhalb des experimentellen Lymphangioms. Mit Hilfe des Pan-Endothelmarkers CD31 (Müller et al. 1989; Albelda et al. 1990; Ayalon et al. 1994) ließen sich sowohl lymphatische als auch blutendotheliale Zellen darstellen. Der Pan-Leukozytenmarker CD45 (Trowbridge 1978; Standring et al. 1978; Sunderland et al. 1979; Hoessli und Vassalli 1980; Dalchau et al. 1980) wurde eingesetzt, um das Ausmaß der inflammatorischen Reaktion gegen das injizierte FIA abzuschätzen. 


\section{Material und Methoden}

\subsection{Experimentelle Lymphangiome}

Die experimentellen Mauslymphangiome wurden nach Mancardi et al. (1999) durch zweimalige intraperitoneale Injektion von 0,2 ml Freund's Incomplete Adjuvant (FIA) in 8-12 Wochen alten Balb/c-Mäusen induziert. Das FIA wurde mit gleichen Anteilen an phosphatgepufferter Salzlösung (PBS) verdünnt. Das Intervall zwischen den i.p. Injektionen betrug zwei Wochen. Die Induktion der Lymphangiome habe ich in Kooperation mit Herrn Dr. H.A. Weich am HZI in Braunschweig durchgeführt. Ein genehmigter tierexperimenteller Antrag liegt vor (Aktenzeichen: 33.11.42502-04/07-10.05). Die Lymphangiome $(n=8)$ manifestierten sich innerhalb von 2 Wochen nach der letzten Injektion und waren zumeist mit dem Diaphragma oder der Leber vergesellschaftet (Abb. 1). Die Mäuse wurden mit $\mathrm{CO}_{2}$ betäubt, durch Genickbruch getötet und das Tumorgewebe reseziert.

\subsection{Fixierung und Einbettung der Präparate}

Anschließend wurde das Gewebe für 10min in 4\% Paraformaldehyd (PFA) fixiert, für $3 \times 15 \mathrm{~min}$ in 0,1 M Kaliumphosphat-Puffer (KPP) gespült und für 30min in 5\% Saccharose-Lösung gegeben. Darauf folgte 1 Stunde Inkubation in 15\% Saccharose-Lösung bei Raumtemperatur. Die Einbettung wurde in Kryomedium (Tissue Tek) mit anschließender Aushärtung bei $-20^{\circ} \mathrm{C}$ vorgenommen. Einige Präparate wurden nach der Fixierung über eine aufsteigende Alkoholreihe entwässert und über Rotihistol in Paraffin $\left(58^{\circ} \mathrm{C}\right)$ überführt. Am folgenden Tag erfolgte das Einbetten in Paraffinblöcke.

\subsection{Herstellung der Gefrierschnitte}

Mittels Kryomikrotom (Leica CM 30505, Bensheim, Deutschland) wurden Gewebeschnitte von 16-20 $\mu \mathrm{m}$ Dicke angefertigt, auf beschichtete Objektträger (Superfrost Plus, Menzel Gläser) aufgetragen und bei $-20^{\circ} \mathrm{C}$ aufbewahrt. Die bestückten Objektträger wurden vor der Immunfloureszenzfärbung für 1 Stunde bei Raumtemperatur aufgetaut. 


\subsection{Herstellung der Paraffinschnitte}

Mittels Paraffinmikrotom (Leica 2035 Biocut, Nussloch, Deutschland) wurden Gewebeschnitte von $8 \mu \mathrm{m}$ Dicke angefertigt und auf mit Eiweiß-Glycerin (Division Chroma, Waldeck GmbH Münster) beschichtete Objektträger aufgetragen. Vor der Immunfluoreszenzfärbung wurden die Paraffinschnitte zunächst für 2 x 5min in Xylol gegeben, darauf in einer in 10\%-Schritten absteigenden Ethanolreihe (100\% - 30\%) für jeweils 3min gewaschen und anschließend in Aqua dest. gegeben.

\subsection{Immunfluoreszenz-Färbung}

Zur Vermeidung unspezifischer Bindung der Antikörper, wurden die Gewebeschnitte für 1 Stunde in 1\% BSA-Lösung (Bovines-Serum-Albumin in PBS) bei Raumtemperatur inkubiert.

Die Applikation des primären Antikörpers erfolgte in der jeweiligen Konzentration, wie sie Tabelle 1 zu entnehmen ist. Die Inkubationszeit betrug 1 Stunde, nur bei anti-Prox1Antikörpern wurde über Nacht bei $4^{\circ} \mathrm{C}$ inkubiert. Anschließend wurden die Objektträger zweimal mit 0,1 M Kaliumphosphat-Puffer (KPP) zur Entfernung des nicht gebundenen primären Antikörpers gespült. Die sekundären Antikörper (Verdünnung 1:200 siehe Tabelle 2) wurden zur Vermeidung von Artefakten durch Fluoreszenzkristalle zuvor für 5min bei 10000 Umdrehungen zentrifugiert. Die Inkubationszeit betrug 1 Stunde. Anschließend wurden die Objektträger zweimal mit 0,1 M Kaliumphosphat-Puffer (KPP) gewaschen. Die Inkubationszeit mit Dapi (Konzentration 1: 20 000), einem Farbstoff mit hoher Affinität zu den Zellkernen, betrug $5 \mathrm{~min}$. Anschließend wurden die Objektträger zweimal mit 0,1 M Kaliumphosphat-Puffer (KPP) gewaschen und mit Fluoromount-G unter Deckgläschen eingedeckt.

\subsection{Verwendete Antikörper}

Die Tabellen 1 und 2 zeigen die von mir verwendeten primären und sekundären Antikörper. Die Anfertigung der angegebenen Verdünnung erfolgte dabei immer mit 0,1 M KPP-Lösung. 
Tabelle1: Primäre Antikörper

\begin{tabular}{|l|l|l|}
\hline Primärer Antikörper & Hersteller & Verdünnung \\
\hline $\begin{array}{l}\text { Alpha-SMA } \\
\text { (rabbit-anti-human) }\end{array}$ & Abcam, Cambridge, UK & $1: 1000$ \\
\hline $\begin{array}{l}\text { CD31 / PECAM1 } \\
\text { (rat-anti-mouse) }\end{array}$ & $\begin{array}{l}\text { BD Pharmington, San Diego, } \\
\text { USA }\end{array}$ & $1: 100$ \\
\hline $\begin{array}{l}\text { CD45 } \\
\text { (rat-anti-mouse) }\end{array}$ & $\begin{array}{l}\text { BD Pharmington, San Diego, } \\
\text { USA }\end{array}$ & $1: 50$ \\
\hline $\begin{array}{l}\text { Lyve1 } \\
\text { (rabbit-anti-mouse) }\end{array}$ & Regeneron, Tarrytown, NY & $1: 100$ \\
\hline $\begin{array}{l}\text { Meca32 } \\
\text { (rat-anti-mouse) }\end{array}$ & DSHB, Iowa, USA & $1: 100$ \\
\hline $\begin{array}{l}\text { Podoplanin / G8.8 } \\
\text { (hamster-anti-mouse) }\end{array}$ & DSHB, Iowa, USA & $1: 1000$ \\
\hline $\begin{array}{l}\text { Prox1 } \\
\text { (rabbit-anti-human) }\end{array}$ & $\begin{array}{l}\text { Reliatech, Braunschweig, } \\
\text { Deutschland }\end{array}$ & $1: 1000$ \\
\hline $\begin{array}{l}\text { VEGFR-2 } \\
\text { (rat-anti-mouse) }\end{array}$ & $\begin{array}{l}\text { BD Pharmington, San Diego, } \\
\text { USA }\end{array}$ & $1: 100$ \\
\hline $\begin{array}{l}\text { VEGFR-3 } \\
\text { (rat-anti-mouse) }\end{array}$ & $\begin{array}{l}\text { eBioscience, Frankfurt, } \\
\text { Deutschland }\end{array}$ & $1: 50$ \\
\hline
\end{tabular}

Tabelle 2: Sekundäre Antikörper

\begin{tabular}{|l|l|l|}
\hline Sekundärer Antikörper & Hersteller & Verdünnung \\
\hline $\begin{array}{l}\text { Alexa-488 } \\
\text { goat-anti-rat IgG }\end{array}$ & $\begin{array}{l}\text { Molecular Probes, Leiden, } \\
\text { Niederlande }\end{array}$ & $1: 200$ \\
\hline $\begin{array}{l}\text { Alexa-488 } \\
\text { goat-anti-hamster IgG }\end{array}$ & $\begin{array}{l}\text { Molecular Probes, Leiden, } \\
\text { Niederlande }\end{array}$ & $1: 200$ \\
\hline $\begin{array}{l}\text { Alexa-594 } \\
\text { donkey-anti-rabbit IgG }\end{array}$ & $\begin{array}{l}\text { Molecular Probes, Leiden, } \\
\text { Niederlande }\end{array}$ & $1: 200$ \\
\hline
\end{tabular}

\subsection{HE-Färbung nach Mayer}

Die Paraffinschnitte wurden zunächst für 2 x $5 \mathrm{~min}$ in Xylol entparaffiniert, darauf in einer in 10\%-Schritten absteigenden Ethanolreihe (100\% - 30\%) für jeweils 3min rehydriert und anschließend in Aqua dest. gewässert. Die Objektträger wurden dann für $3 \mathrm{~min}$ in Hämatoxylin (nach Mayer) gegeben und danach für 10min unter fließendem Wasser gespült. Dann wurden die Paraffinschnitte für 3min in Eosin-Lösung gegeben, anschließend in Aqua dest. gewaschen und über eine in 10\%-Schritten aufsteigende Ethanolreihe (30\% - 100\%) entwässert. Nach Überführung in Xylol wurden die Objektträger unter dem Abzug unter Deckgläschen mit Entellan eingedeckt. 


\subsection{Verwendete Lösungen}

Im Folgenden werden die verschiedenen Lösungen und Puffer beschrieben, die ich im Rahmen der Immunhistologie und HE-Färbung eingesetzt habe.

0,1 M Kaliumphosphat-Puffer (KPP):

1,088g Kalium-dihydrogenphosphat

13,92g di-Kaliumhydrogenphosphat

wurden in $880 \mathrm{ml}$ Aqua dest. gelöst.

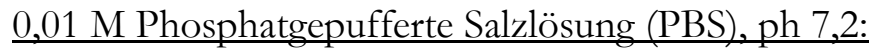

$72,0 \mathrm{~g}$ Natriumchlorid

14,8g di-Natriumhydrogenphosphat

4,3g Kalium-dihydrogenphosphat

wurden in einem Liter Aqua dest. gelöst.

1\% BSA in PBS:

$1 \mathrm{~g}$ Bovines Serum Albumin wurde in $100 \mathrm{ml}$ phosphatgepufferter Salzlösung gelöst.

\section{4\% PFA-Lösung:}

40g Paraformaldehyd (PFA) werden in $800 \mathrm{ml}$ Aqua dest. auf $60^{\circ} \mathrm{C}$ erhitzt. Anschließend werden $200 \mathrm{ml} \mathrm{0,6} \mathrm{M} \mathrm{PBS} \mathrm{dazu} \mathrm{gegeben} \mathrm{und} \mathrm{die} \mathrm{Lösung} \mathrm{filtriert.}$

\section{Eosin-Lösung:}

$2 \mathrm{~g}$ Eosin werden in $1000 \mathrm{ml}$ Aqua dest. gegeben.

\section{Hämatoxylin (nach Mayer):}

1g Hämalaun in $1000 \mathrm{ml}$ Aqua dest.

$0,2 \mathrm{~g} \mathrm{NaJ} 3$

$50 \mathrm{~g}$ Kalilaun (Kaliumaluminiumsulfat)

50g Chloralhydrat

1g Zitronensäure 


\subsection{Verwendete Materialien und Geräte}

\section{Materialien:}

Aqua dest.

eigene Anlage

Chloralhydrat

Merck, Darmstadt

Deckgläser 20x60 mm

Menzel Gläser

Eiweiß-Glycerin aus Hühnereiweiß

Division Chrom Waldeck GmbH, Münster

Entellan

Merck, Darmstadt

Eosin

Merck, Darmstadt

Essigsäure

Merck, Darmstadt

Ethanol

Fluoromount-G

Merck, Darmstadt

Southern Biotechnology Associates, Birmingham,

Großbritannien

Hämalaun

Merck, Darmstadt

Kaliumaluminiumsulfat

Merck, Darmstadt

Kalium-dihydrogenphosphat

Merck, Darmstadt

di-Kaliumhydrogenphosphat

Merck, Darmstadt

Kernmarker Dapi

1:20 000 in PBS

Natriumchlorid

Roth, Karlsruhe

di-Natriumhydrogenphosphat

Merck, Darmstadt

Natriumjodit

Merck, Darmstadt

Objektträger

Superfrost Plus, Menzel Gläser

Tissue Tek Kryomedium

Sakura Finetek Europe, Zoeterwoude,

Niederlande

Xylol

Merck, Darmstadt

Zitronensäure

Merck, Darmstadt 


\section{Geräte:}

Epifluoreszenz-Mikroskop

Kryomikrotom

Kühlschrank

Lichtmikroskop

Paraffinmikrotom

Pipetten

Pipettenspitzen

Zentrifuge
Leica DM5000B, Bensheim, Deutschland Leica CM 30505, Bensheim, Deutschland Liebherr Premium, Ochsenhausen, Deutschland

Zeiss, Jena, Deutschland

Leica 2035 Biocut, Nussloch, Deutschland Eppendorf Research / Gilson Pipetman Eppendorf, Hamburg, Deutschland Eppendorf Zentrifuge 5415R, Hamburg, Deutschland 


\section{Ergebnisse}

\subsection{Makroskopische und mikroskopische Aspekte der Lymphangiome}

Die experimentellen Mauslymphangiome, die ich untersucht habe, waren wie bei Mancardi et al. (1999) durch die zweimalige intraperitoneale Injektion von Freund's incomplete adjuvant (FIA) in 8-12 Wochen alten Balb/c-Mäusen induziert worden. 2 Wochen nach der letzten Injektion zeigten sich zahlreiche experimentelle Lymphangiome, die als weißliche Tumoren dem Diaphragma und der Leber aufgelagert waren (Abb. 1). Ich habe ausschließlich die Tumoren untersucht, die sich auf dem Diaphragma entwickelt hatten. Diese Tumoren waren von variabler Größe und zeigten mikroskopisch sowohl zelldichtes Stroma als auch Zysten, die, wie beim Herauspräparieren deutlich wurde, offensichtlich FIA enthielten (Abb. 2).

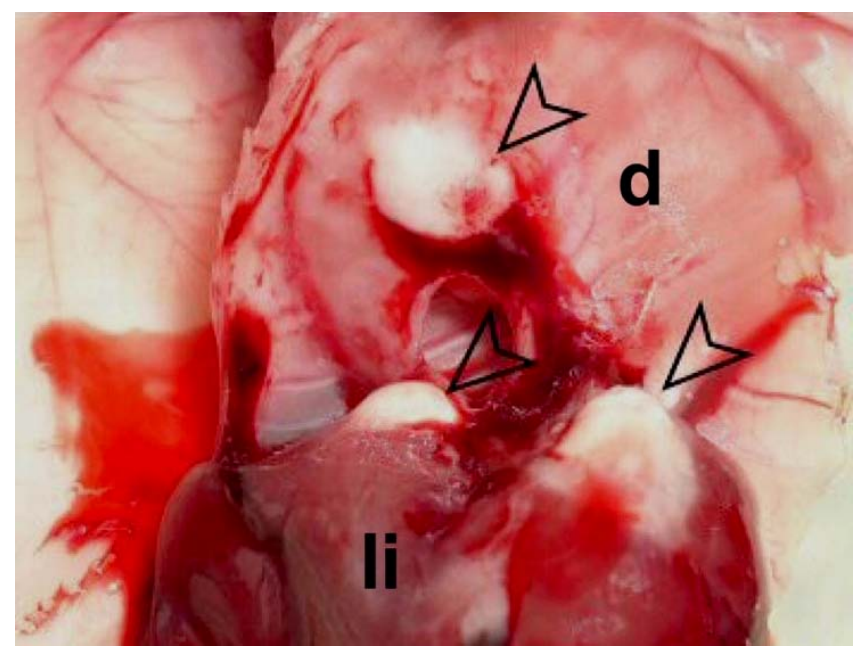

Abb. 1: Abdomen einer mit FIA behandelten Balb/c-Maus. Diaphragma (d), Leber (li). Die Pfeile zeigen auf Lymphangiome, die als solide weiße Tumoren erscheinen.
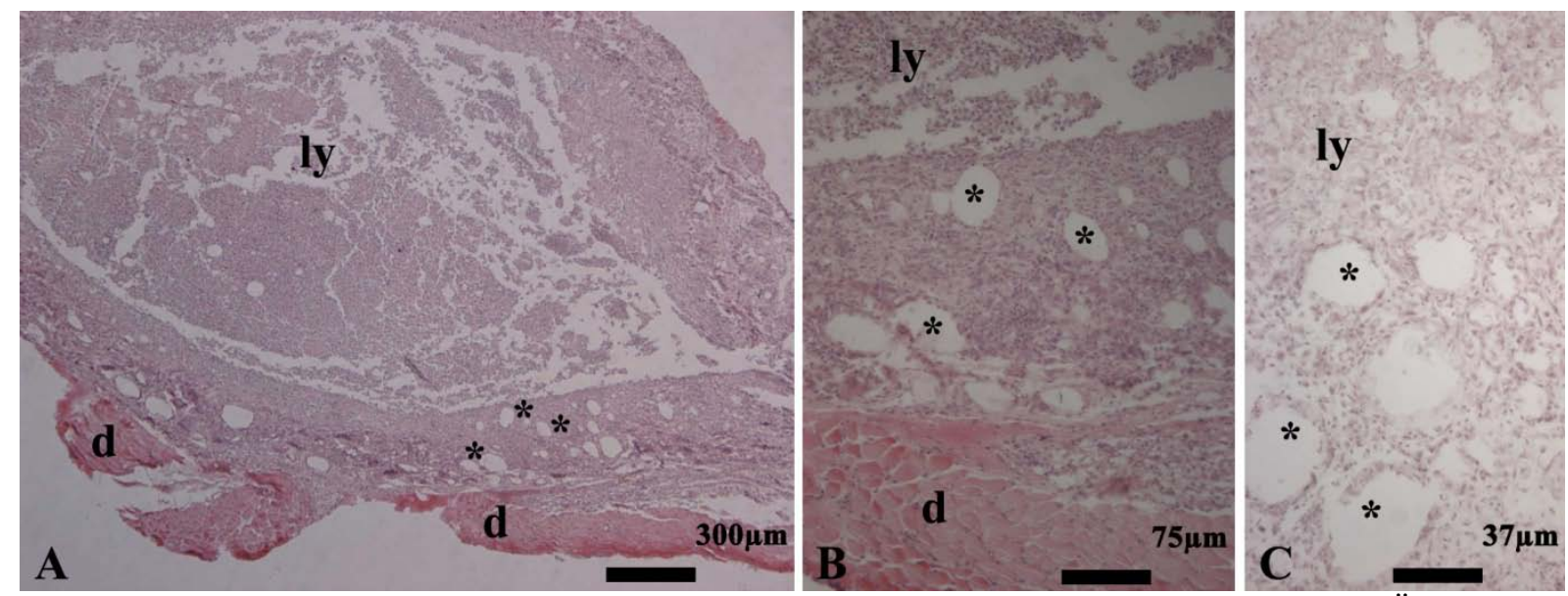

Abb. 2: HE-Färbung eines Paraffinschnitts: A) Experimentelles Lymphangiom im Überblick, B) Ausschnittsvergrößerung aus A, C) Ausschnittsvergrößerung aus B. Es sind das Diaphragma (d) und ein Lymphangiom (ly) zu erkennen. Innerhalb des Lymphangioms (ly) sind zystenartige Hohlräume mit (*) gekennzeichnet (A-C verändert nach Kasten et al. 2007, S. 2956) 


\subsection{Immunfluoreszenzfärbungen mit anti-CD45- und anti-Lyve1-}

\section{Antikörpern}

Zur genaueren Charakterisierung der Tumoren habe ich Immunfluoreszenzfärbungen durchgeführt. Die Untersuchung der Lymphgefäße erfolgte hierbei durch Antikörper gegen den Hyaluronsäure-Rezeptor Lyve1, einem lymphendothelspezifischen Marker, den ich in Doppelfärbungen sowohl mit dem Pan-Leukozytenmarker CD45 als auch mit anderen Lymphendothelmarkern wie Prox1 und Podoplanin, sowie dem Pan-Endothelmarker CD31 kombiniert habe. Die Färbungen mit Antikörpern gegen den Pan-Leukozytenmarker CD45 zeigen, dass der Großteil der Tumoren aus Leukozyten besteht (Abb. 3, 4).
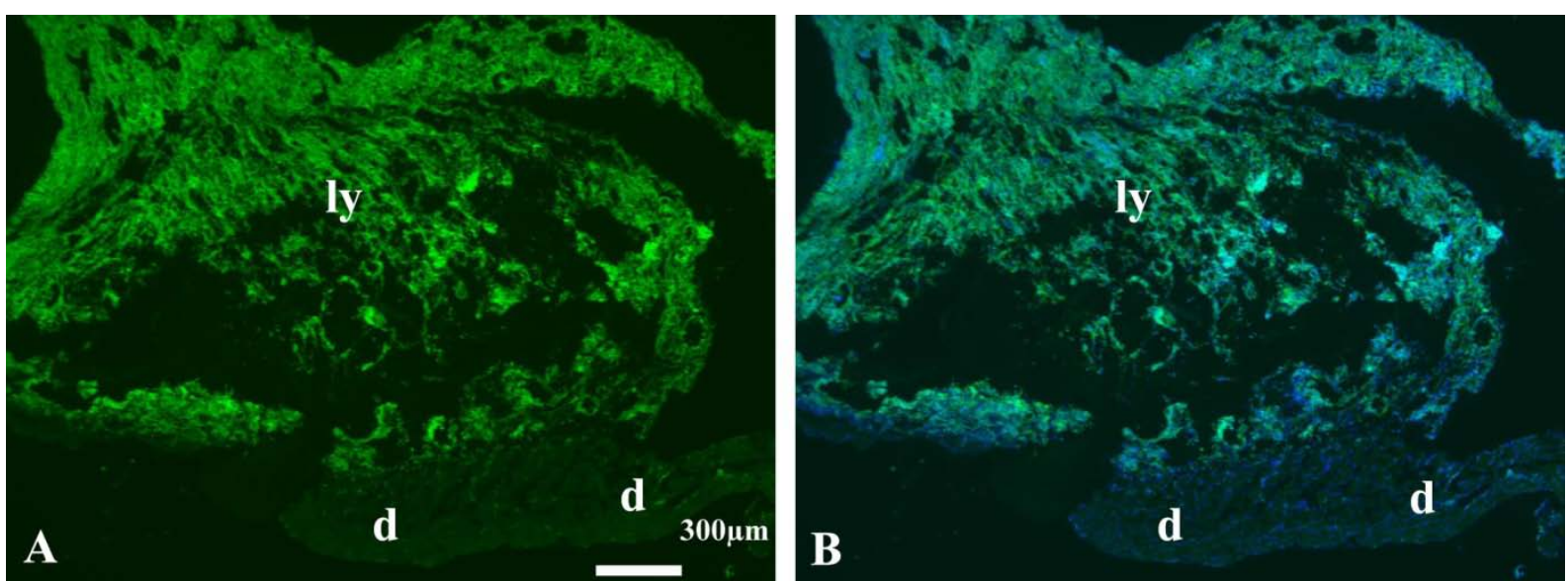

Abb. 3: Färbung eines Gefrierschnitts mit anti-CD45-Antikörpern: A) CD45 (grün),

B) zusammengesetztes Bild mit Kernmarker Dapi (blau). Es sind das Diaphragma (d) und ein Lymphangiom (ly) zu erkennen. CD45-positive Leukozyten (grün) sind im gesamten Lymphangiom gleichmäßig verteilt.
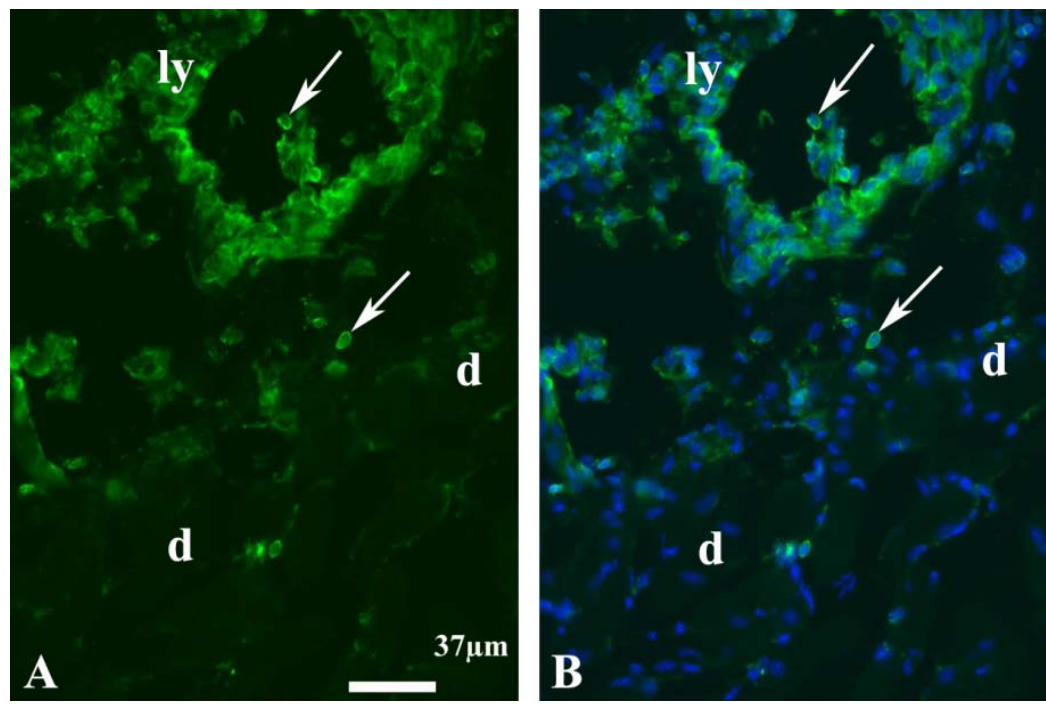

Abb. 4: Färbung eines

Gefrierschnitts mit antiCD45-Antikörpern: A) CD45 (grün), B) zusammengesetztes Bild mit Dapi (blau). Es ist der Übergang vom Diaphragma (d) in ein Lymphangiom (ly) zu sehen. CD45-positive Leukozyten sind mit Pfeilen markiert. 
In den Doppelfärbungen, die ich mit anti-Lyve1- und anti-CD45-Antikörpern durchgeführt habe, konnte ich beobachten, dass zum Zeitpunkt meiner Untersuchung die Lymphgefäße, welche scheinbar vom Diaphragma aus kontinuierlich in das Lymphangiom aussprossen, noch nicht in den gesamten Tumor vorgedrungen waren (Abb. 5, 6). Zum anderen stellten sich die Tumoren auch in den Doppelfärbungen als eine massive Ansammlung von Leukozyten dar, welche offensichtlich der Ausdruck einer inflammatorischen Reaktion auf das FIA ist (Abb. 6).

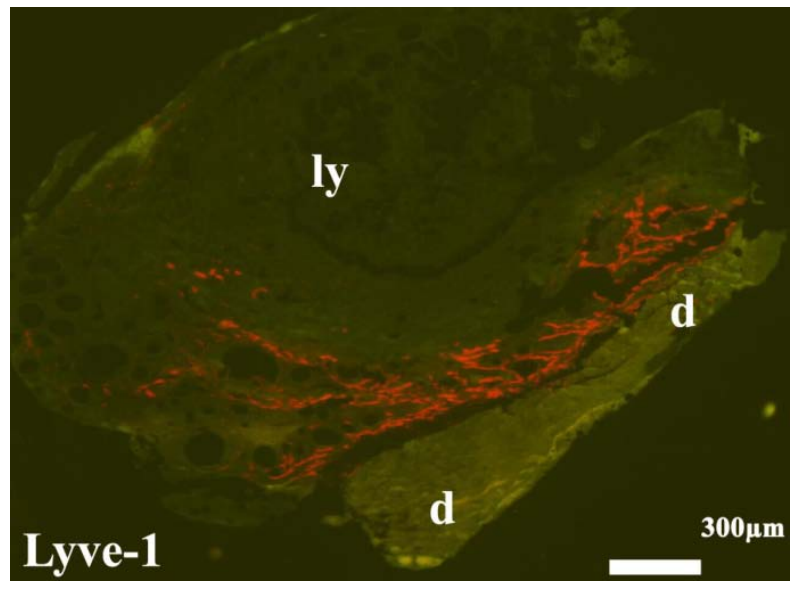

Abb. 5: Färbung eines Paraffinschnitts mit anti-Lyve1-Antikörpern: Zu sehen sind Lyve1-positive Lymphgefäße (rot), die vor allem in dem an das Diaphragma angrenzenden Bereich (d) lokalisiert sind, während weite Teile des Lymphangioms (ly) lymphgefäßfrei erscheinen. 

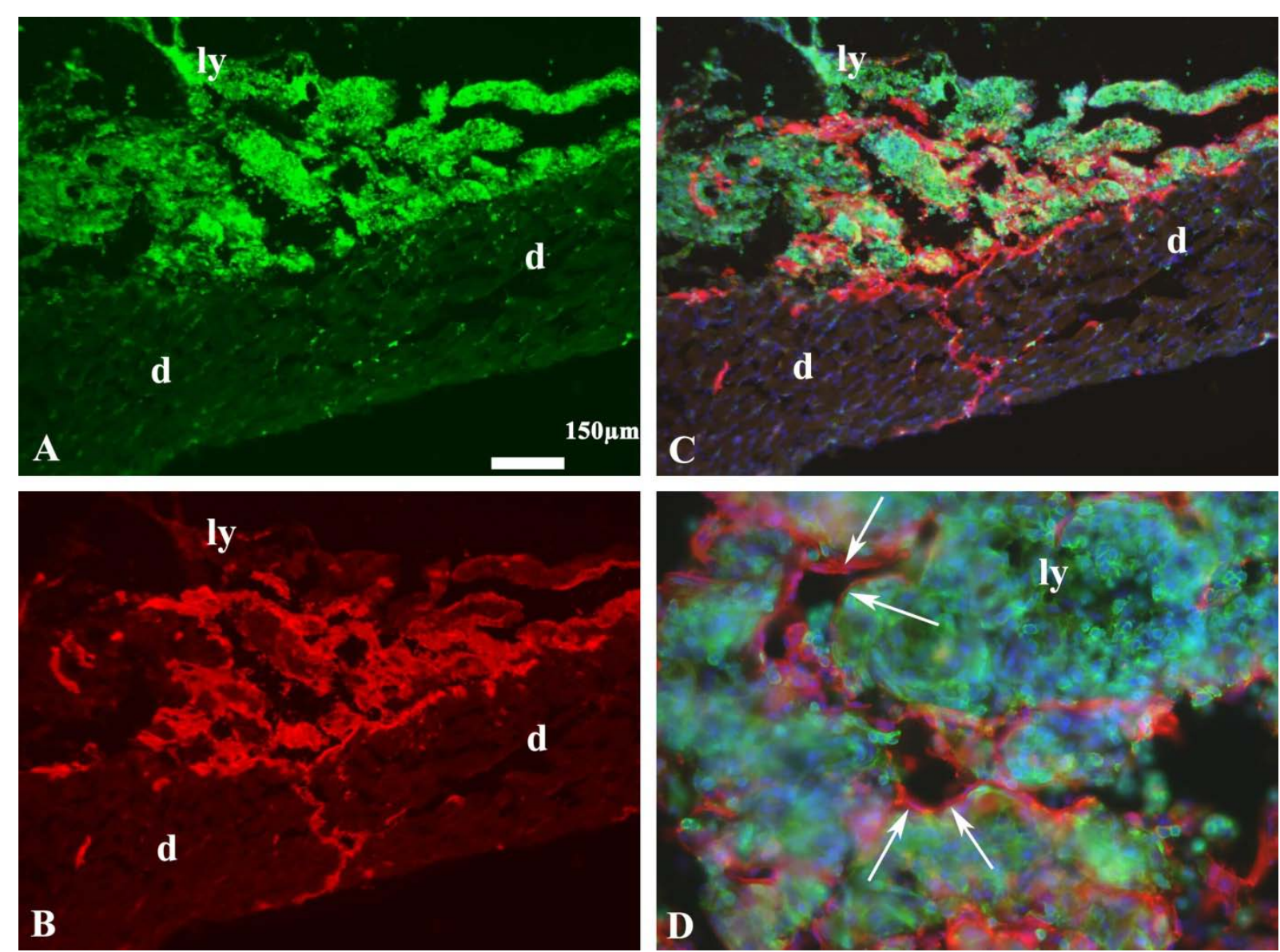

Abb. 6: Doppelfärbung eines Gefrierschnitts mit anti-CD45- und anti-Lyve1-Antikörpern:

A) CD45 (grün), B) Lyve1 (rot), C) zusammengesetztes Bild mit Dapi (blau). A-C) Lyve1 positive Lymphgefäße wachsen vom Diaphragma (d) ausgehend in das Lymphangiom (ly) ein. D) Stärkere Vergrößerung aus C). Lyve1-positive Lymphgefäße innerhalb des Lymphangioms (Pfeile) neben CD45-positiven Leukozyten.

\subsection{Immunfluoreszenzfärbungen mit anti-Prox1-, anti-Lyve1- und anti-CD31-Antikörpern}

Den lymphendothelialen Charakter der anti-Lyve1-positiven Gefäße innerhalb des Tumors konnte ich durch Doppelfärbungen mit Antikörpern gegen den Homeobox-Transkriptionsfaktor Prox1, einen verlässlichen Marker für lymphendotheliale Zellen, bestätigen (Abb 7). Durch die Lokalisation des Homeboxgenproduktes im Zellkern lymphendothelialer Zellen ließen sich mit anti-Prox1-Antikörpern lymphendotheliale Zellkerne nachweisen. Des Weiteren beobachtete ich in Doppelfärbungen auf anti-Prox1-positiven lymphendothelialen Zellen typischerweise eine schwächere Expression des Pan-Endothelmarkers CD31 im Vergleich zu den benachbarten Blutgefäßen, die stets ein stark positives anti-CD31-Signal zeigten (Abb.7, 8). In den von mir durchgeführten Doppelfärbungen mit anti-Lyve1 und anti-CD31 ließ sich diese Beobachtung 
bestätigen (Abb. 9, 10). Eine Unterscheidung zwischen Blut- und Lymphgefäßen in den experimentellen Lymphangiomen ist auf diese Weise möglich.

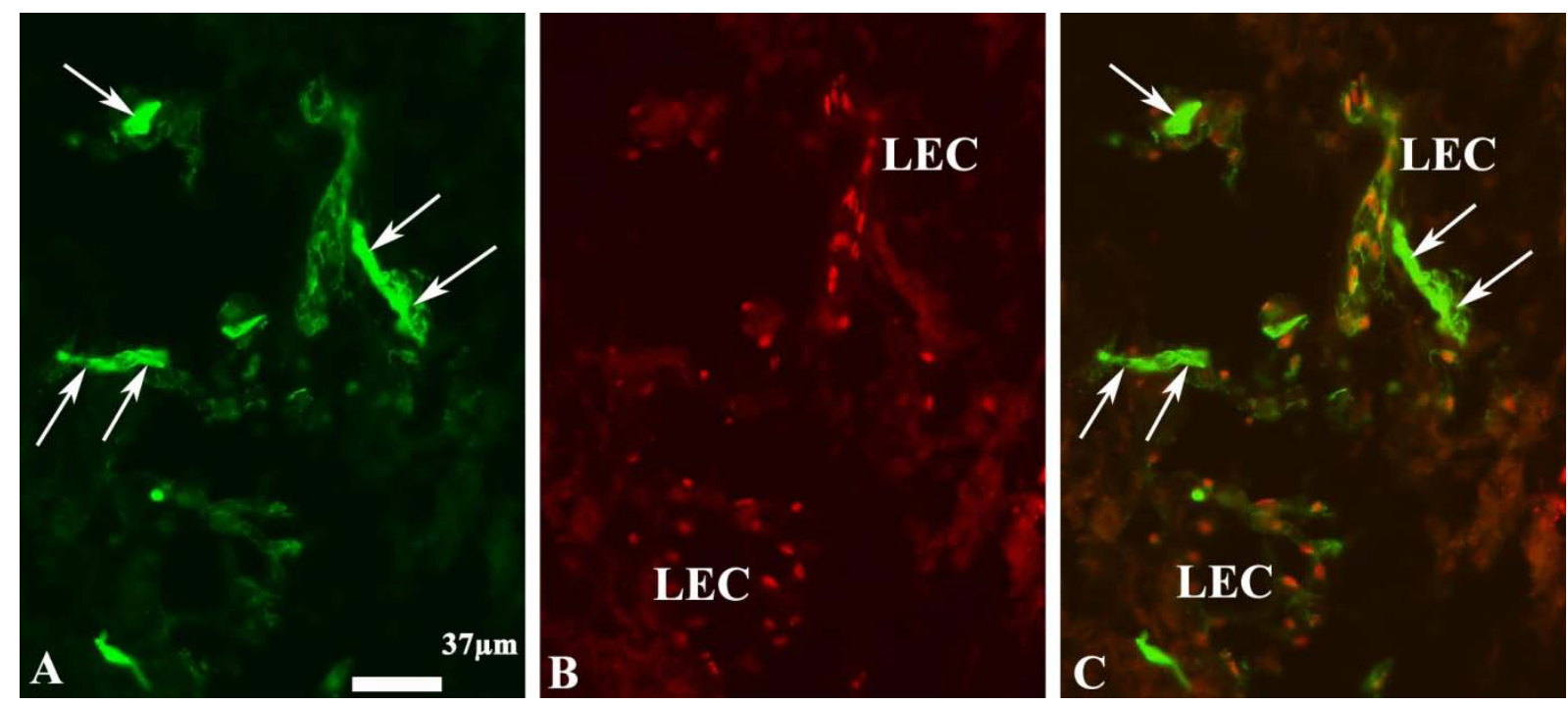

Abb. 7: Doppelfärbung eines Gefrierschnitts mit anti-CD31- und anti-Prox1-Antikörpern: A) CD31 (grün), B) Prox1 (rot), C) zusammengesetztes Bild. A, C) Stark CD31-positive Blutendothelzellen (Pfeile). C) Prox1-positive Zellkerne der Lymphendothelzellen (LEC) sind als rote Strukturen zu erkennen, die von einem schwachen CD31-Signal umgeben sind.

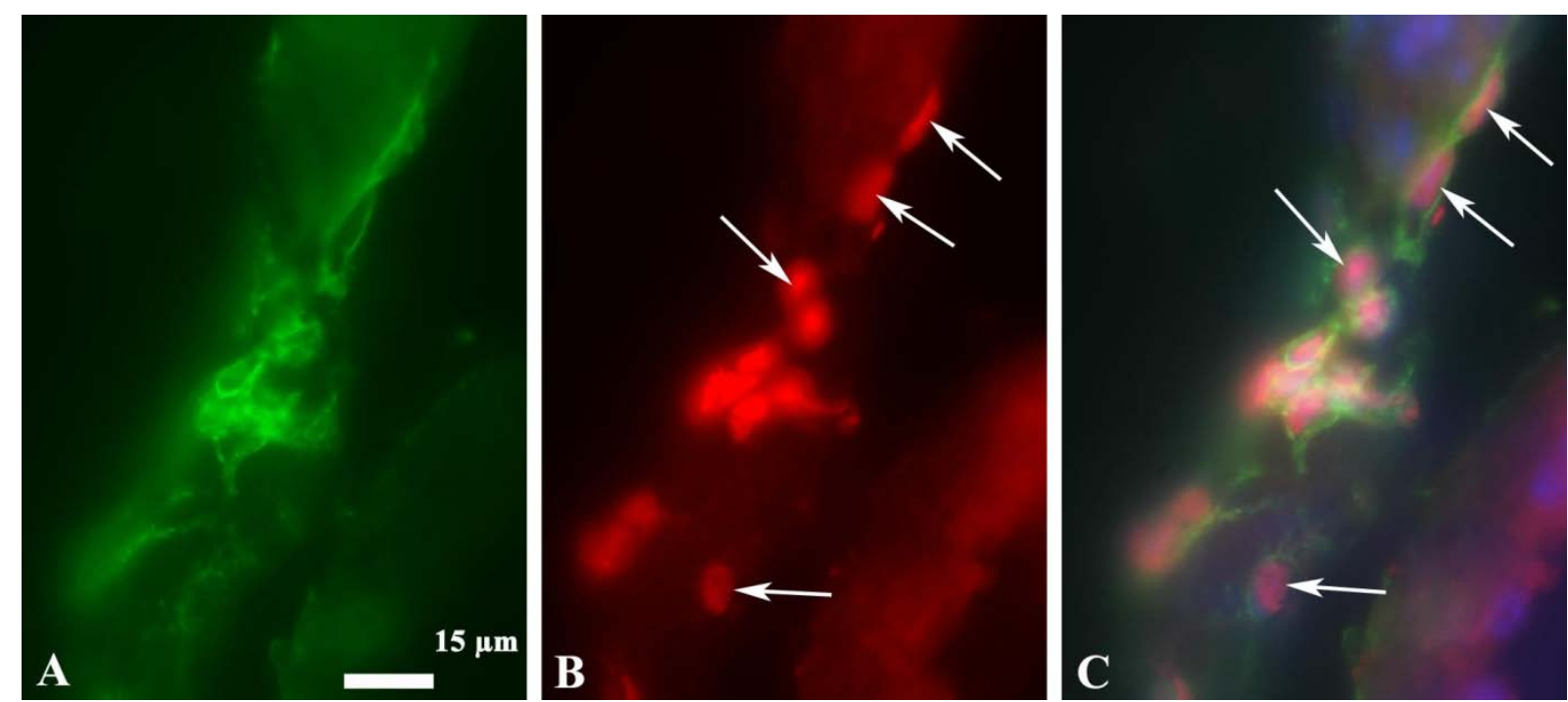

Abb. 8: Doppelfärbung eines Gefrierschnitts mit anti-CD31- und anti-Prox1-Antikörpern: A) CD31 (grün), B) Prox1 (rot), C) zusammengesetztes Bild mit Dapi (blau). A, C) Zarte CD31Expression auf der Zellmembran von Lymphendothelzellen. C) Wegen der Überlagerung mit dem Dapi-Signal erscheinen Prox1-positive Zellkerne (Pfeile) pink. 


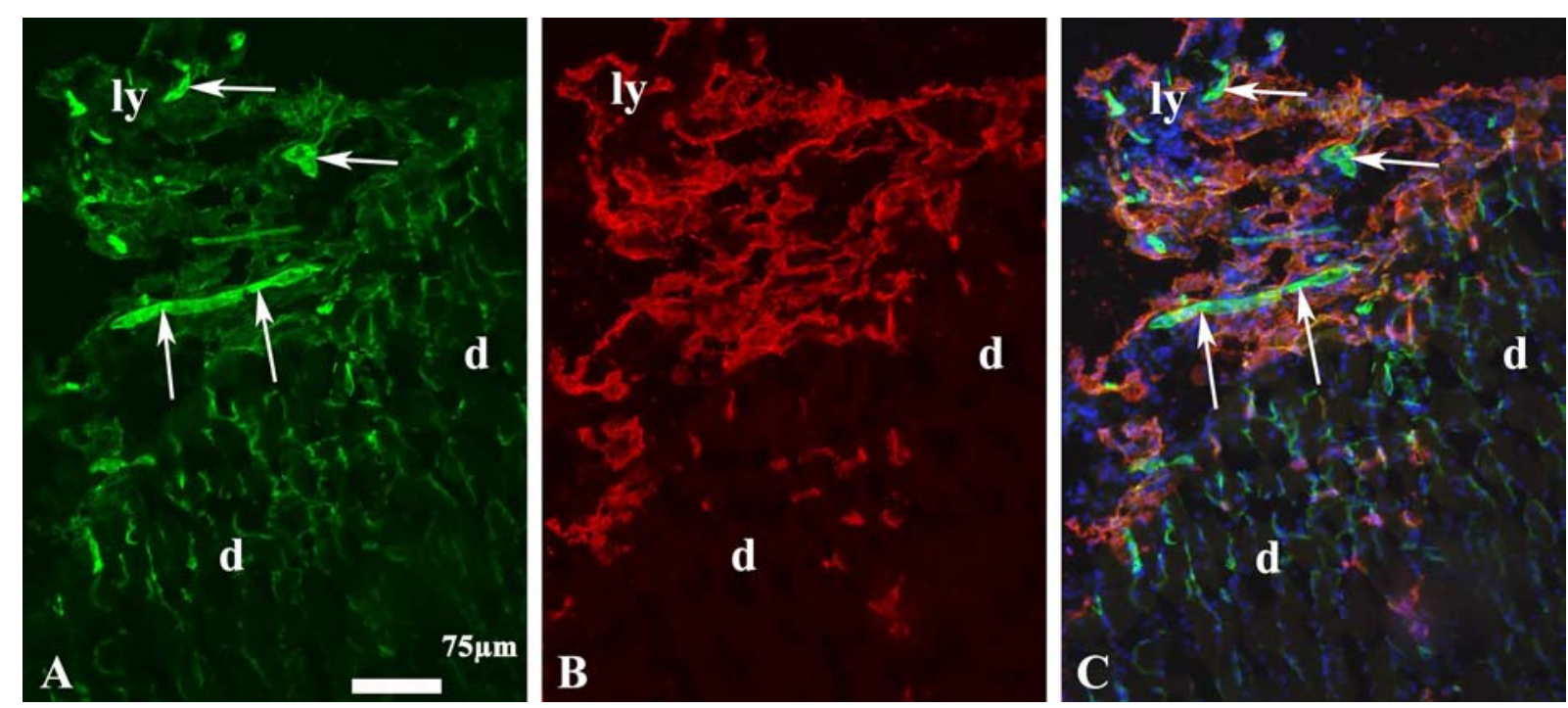

Abb. 9: Doppelfärbung eines Gefrierschnitts mit anti-CD31- und anti-Lyve1-Antikörpern: A) CD31 (grün), B) Lyve1 (rot), C) zusammengesetztes Bild mit Dapi (blau). C) CD31-positive Blutkapillaren (Pfeile) wachsen neben Lyve1-positiven Lymphkapillaren vom Diaphragma (d) ausgehend in das Lymphangiom (ly) ein.
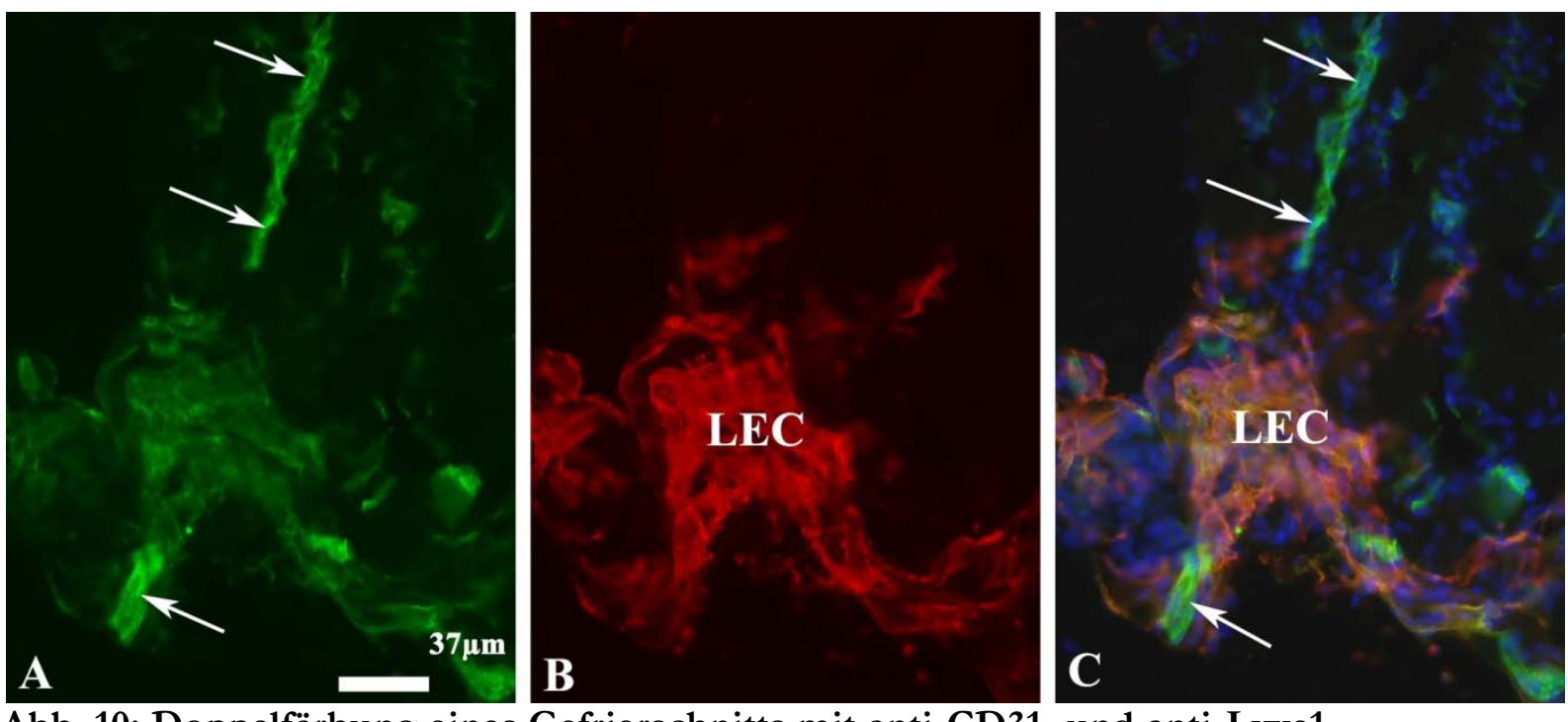

Abb. 10: Doppelfärbung eines Gefrierschnitts mit anti-CD31- und anti-Lyve1-

Antikörpern: A) CD31 (grün), B) Lyve1 (rot), C) zusammengesetztes Bild mit Dapi (blau).

C) CD31-positive Blutendothelzellen von Kapillaren (Pfeile) neben einem Konglomerat von Lymphendothelzellen (LEC), die aufgrund schwacher CD31-Expression ein gelbes Signal aufweisen. (A-C verändert nach Kasten et al. 2007, S. 2956). 


\subsection{Immunfluoreszenzfärbungen mit anti-Podoplanin- und anti-}

\section{Lyve1-Antikörpern}

Die von mir durchgeführten Doppelfärbungen mit Antikörpern gegen Lyve1 und das

Oberflächenglykoprotein Podoplanin zeigten, dass Podoplanin in den Lymphendothelzellen des

Lymphangioms und des Diaphragmas zusammen mit Lyve1 exprimiert wird (Abb.11). Ich

konnte jedoch auch in zahlreichen anti-Lyve1-negativen Zellen, vor allem in Epithelzellen der

Pleura und des Peritoneums, ein Podoplanin-Signal beobachten. Innerhalb des Lymphangioms

schienen außerdem zahlreiche epithelial ausgekleidete Zysten Podoplanin-positiv zu sein (Abb.

11). Eine mögliche Ursache hierfür könnte die Verschleppung von Podoplanin-positiven

Serosazellen bei der Entstehung des Lymphangioms sein. Sicher kann aufgrund meiner

Beobachtungen jedoch nur gesagt werden, dass Podoplanin sowohl von anti-Lyve1-positiven

Lymphendothelzellen, als auch von anti-Lyve1-negativen Epithelzellen der Pleura und des

Peritoneums exprimiert wird und dadurch der alleinige Einsatz von anti-Podoplanin-Antikörpern die Lymphgefäße nicht eindeutig charakterisiert.
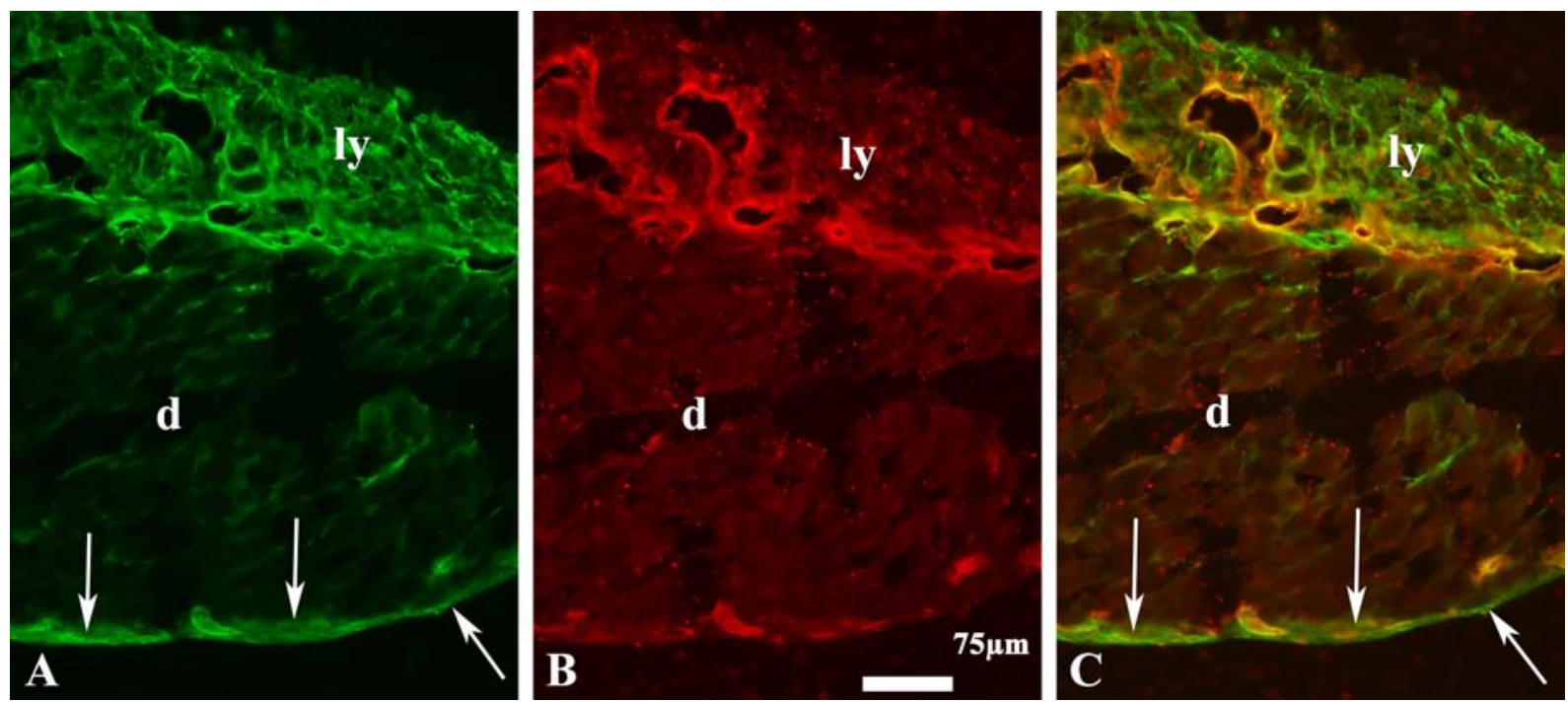

Abb. 11: Doppelfärbung eines Gefrierschnitts mit anti-Podoplanin- und anti-Lyve1Antikörpern: A) Podoplanin (grün), B) Lyve1 (rot), C) zusammengesetztes Bild. A, C) Podoplanin-positive Zellen des Pleuraepithels (Pfeile). C) Lymphendothelzellen besitzen aufgrund der Co-Expression von Podoplanin und Lyve1 ein gelbliches Signal. Zu beachten ist, dass Podoplanin auch in Lyve1-negativen Epithelzellen innerhalb des Lymphangioms (ly) und des Pleuraepithels (Pfeile) exprimiert wird. 


\subsection{Immunfluoreszenzfärbungen mit anti-Meca32- , anti-VEGFR-2- und anti-Lyve1-Antikörpern}

Die von mir durchgeführten Doppelfärbungen mit Antikörpern gegen Meca32 und Lyve1 zeigten zum einen, dass Meca32 ausschließlich in den Blutgefäßen der untersuchten Lymphangiome und des Diaphragmas exprimiert wurde (Abb. 12). Zum anderen waren die Meca32-positiven Blutgefäße zum Zeitpunkt meiner Untersuchung weiter in den Tumor vorgedrungen, als die Lyve1-positiven Lymphgefäße. Bei den Färbungen mit anti-VEGFR-2-Antikörpern konnte ich beobachten, dass dieser Rezeptor ausschließlich in den Blutgefäßen des Lymphangioms exprimiert wurde. In Doppelfärbungen waren die Lyve-1-positiven Lymphgefäße immer VEGFR-2-negativ (Abb. 13). Die Beobachtung, dass VEGFR-2 ausschließlich in den Blutgefäßen des Lymphangioms exprimiert wurde, konnte durch Doppelfärbungen mit antiVEGFR-2- und anti-Prox1-Antikörpern bestätigt werden (Abb. 14). Meine Beobachtungen deuten darauf hin, dass innerhalb des Lymphangioms die Hämangiogenese der Lymphangiogenese voraus geht, wobei die Blutgefäße den Lymphgefäßen offensichtlich als eine Art Leitstruktur dienen. Der Versuch, den lymphendothelspezifischen Rezeptor VEGFR-3 mit Hilfe zweier verschiedener monoklonaler Antikörper nachzuweisen, erbrachte kein zuverlässiges Ergebnis. 

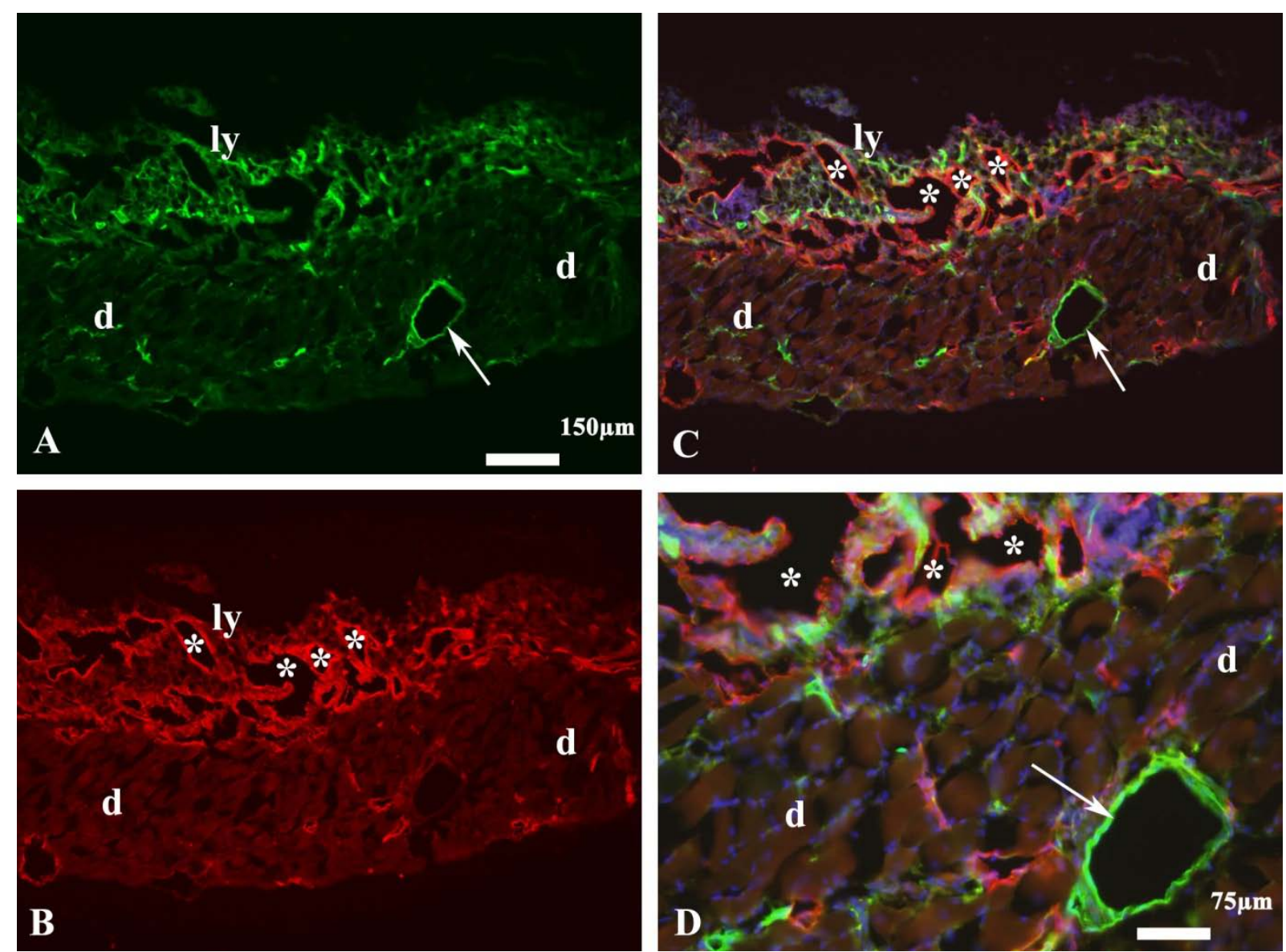

Abb. 12: Doppelfärbung eines Gefrierschnitts mit anti-Meca32- und anti-Lyve1-

Antikörpern: A) Meca32 (grün), B) Lyve1 (rot), C) zusammengesetztes Bild mit Dapi (blau), D) Stärkere Vergrößerung aus C). C, D) Ein großes Meca32-positives Blutgefäß (Pfeil) innerhalb des Diaphragmas (d). Innerhalb des Lymphangioms (ly) sind zahlreiche Meca32-positive Blutgefäße neben Lyve1-positiven zystenartigen Hohlräumen zu sehen (*). 

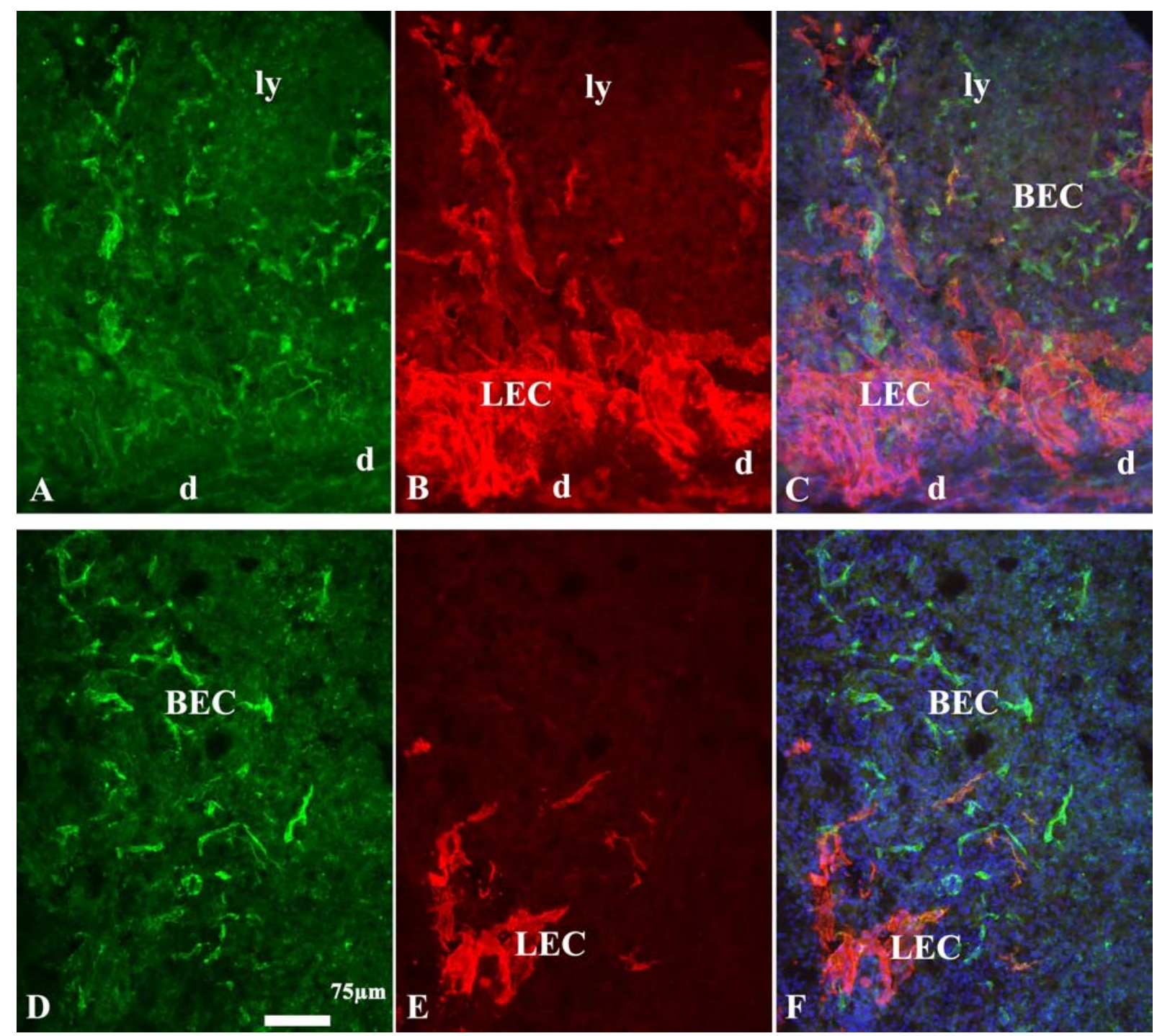

Abb. 13: Doppelfärbung eines Gefrierschnitts mit anti-VEGFR-2- und anti-Lyve1-

Antikörpern: A) VEGFR-2 (grün), B) Lyve1 (rot), C) zusammengesetztes Bild mit Dapi (blau), D) VEGFR-2 (grün), E) Lyve1 (rot), F) zusammengesetztes Bild mit Dapi (blau). A-C) Zahlreiche Lyve1-positive Lymphendothelzellen (LEC), die vom Diaphragma (d) ausgehend in das Lymphangiom (ly) entsprießen. D-F) Bereich innerhalb des Lymphangioms: VEGFR-2positive Blutendothelzellen (BEC) sind zum Zeitpunkt der Untersuchung weiter in das Lymphangiom vorgedrungen, als die Lyve1-positiven Lymphendothelzellen (LEC). 


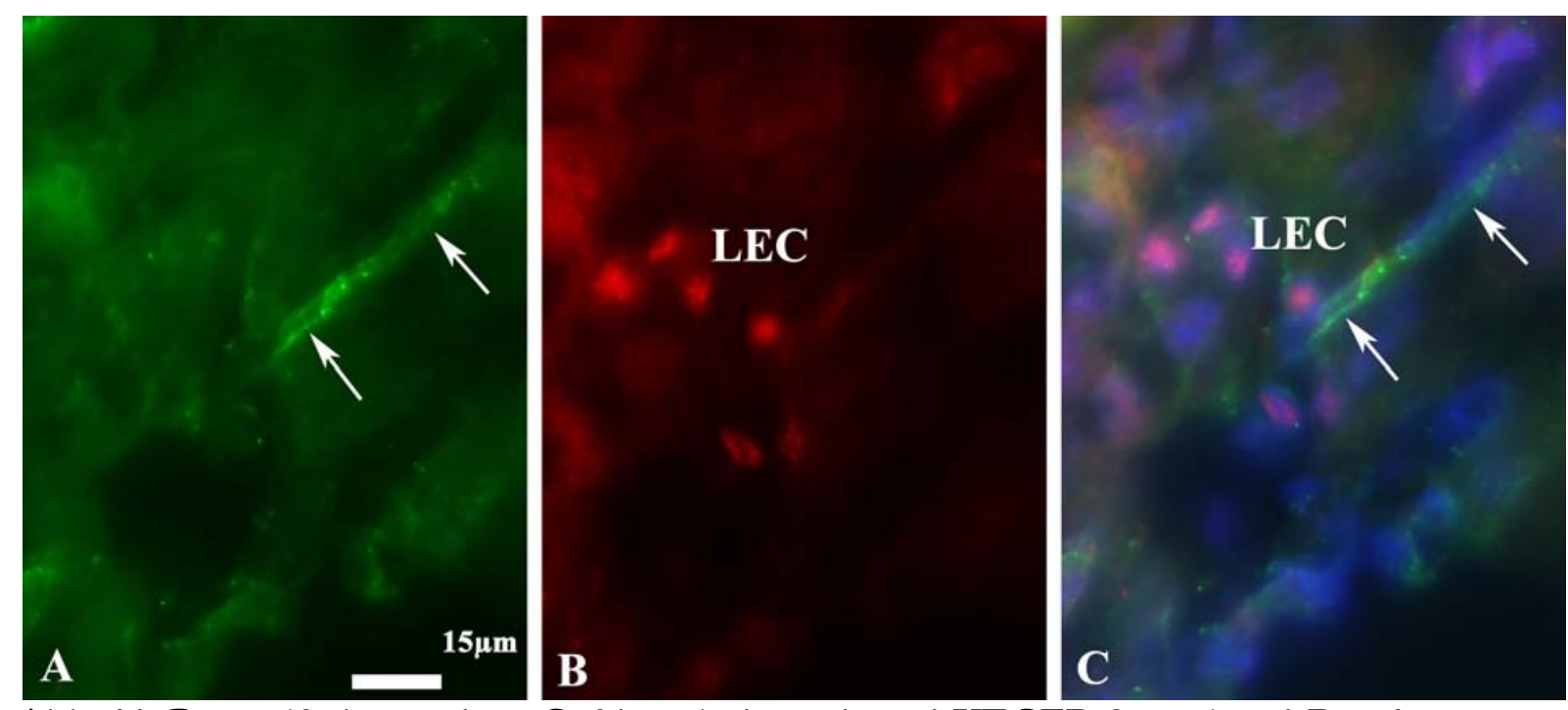

Abb. 14: Doppelfärbung eines Gefrierschnitts mit anti-VEGFR-2- und anti-Prox1-

Antikörpern: A) VEGFR-2 (grün), B) Prox1 (rot), C) zusammengesetztes Bild mit Dapi (blau). C) Ein VEGFR-2-positives Blutgefäß (Pfeile) neben Prox1-positiven Zellkernen von Lymphendothelzellen (LEC) eines Lymphgefäßes, das keine VEGFR-2-Expression aufweist.

\subsection{Immunfluoreszenzfärbungen mit anti-alpha-SMA- und anti- CD31-Antikörpern}

Bei den Blutgefäßen innerhalb des Lymphangioms konnte ich unterschiedliche

Differenzierungsgrade beobachten. Einige der Blutgefäße besaßen eine Tunica media, die sich mit Antikörpern gegen alpha-SMA, dem typischen Aktin der glatten Muskelzellen, anfärben ließ

(Abb. 15, 16). In Doppelfärbungen mit anti-CD31- und anti-alpha-SMA-Antikörpern konnten so verschiedene Gefäßtypen innerhalb des Lymphangioms charakterisiert werden (Abb. 16). Dabei können Gefäße die sowohl alpha-SMA als auch CD31 exprimieren dem arteriellen oder venösen Blutgefäßsystem zugeordnet werden, während es sich bei den stark anti-CD31-positiven, antialpha-SMA-negativen Gefäßen um Blutgefäßkapillaren und bei schwach anti-CD31-positiven, anti-alpha-SMA-negativen Gefäßen um Lymphgefäße handelt. 


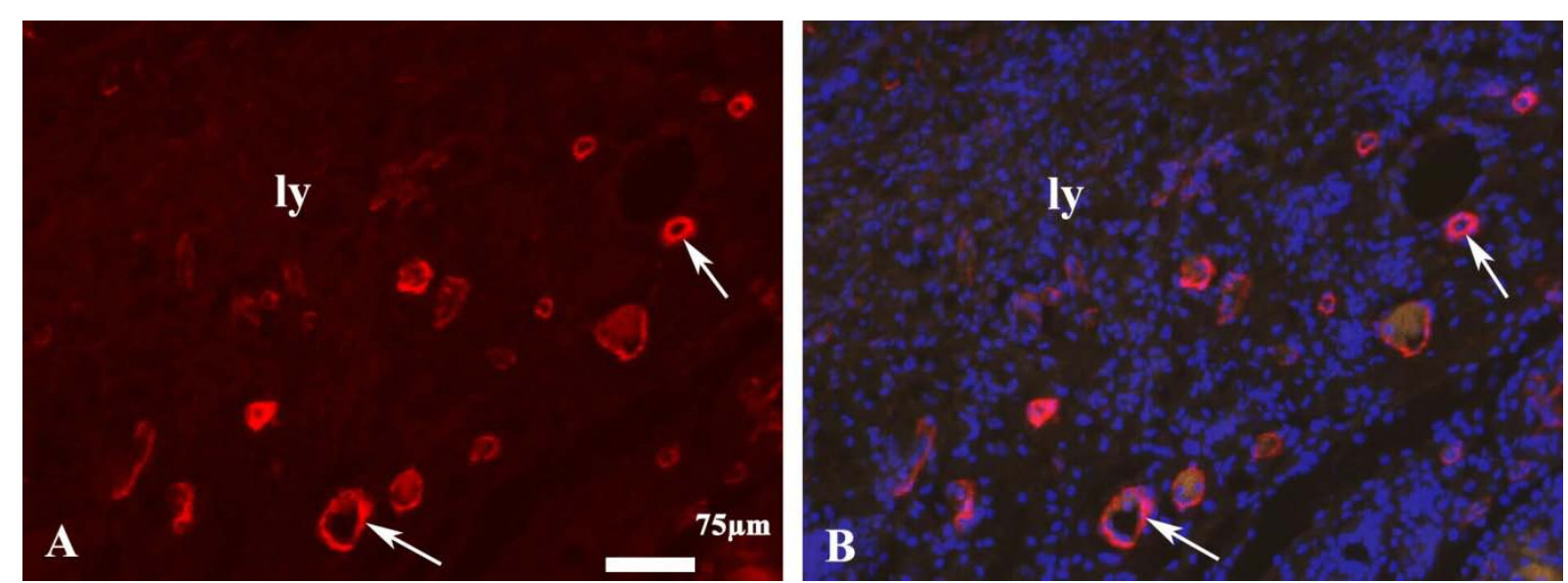

Abb. 15: Färbung eines Paraffinschnitts mit anti-alpha-SMA-Antikörpern:

A) Alpha-SMA (rot), B) zusammengesetztes Bild mit Dapi (blau). Zu sehen sind mehrere quer angeschnittene Blutgefäße innerhalb eines Lymphangioms. Die Tunica media von zwei Blutgefäßen wurde mit Pfeilen gekennzeichnet.
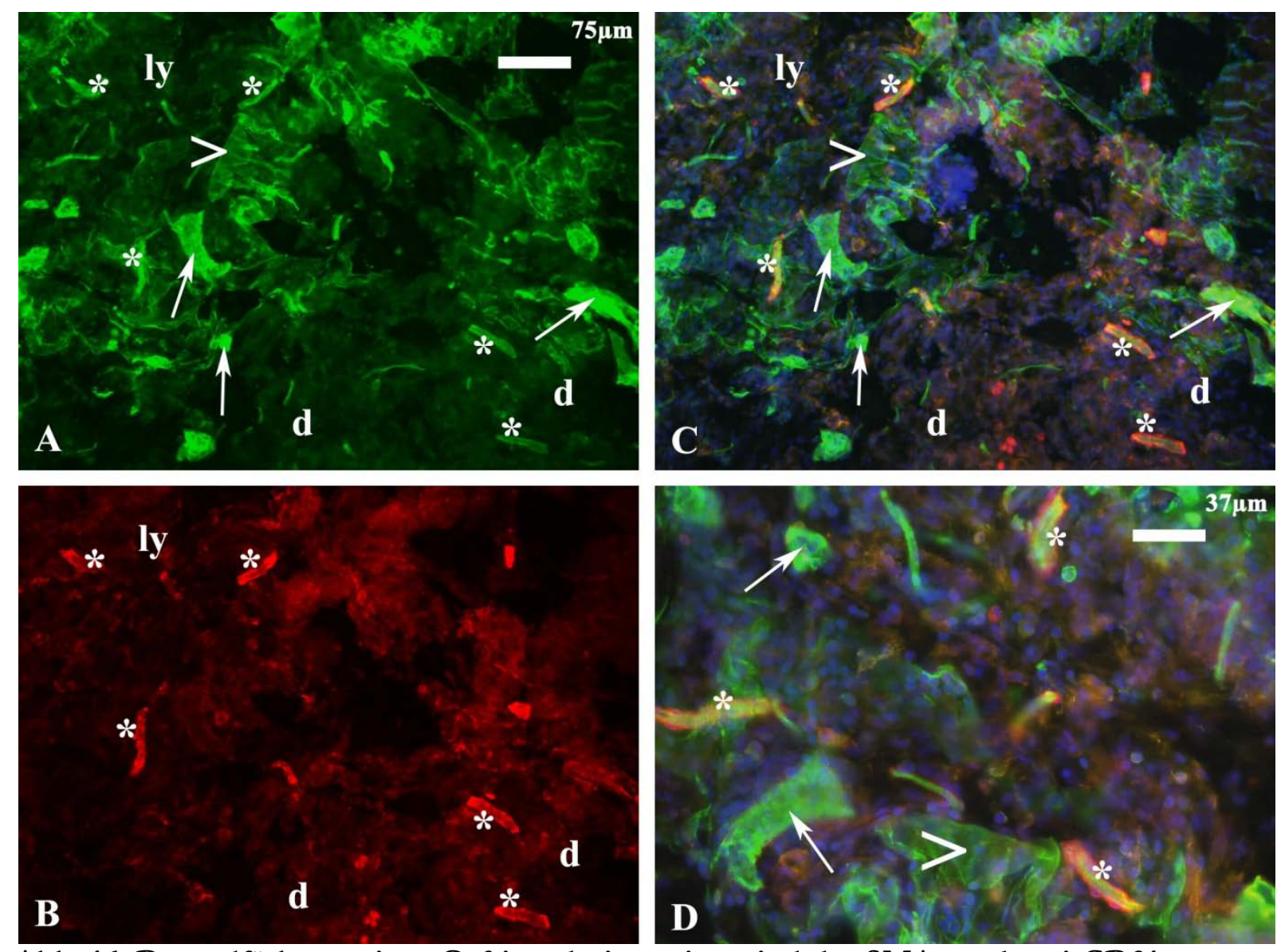

Abb. 16: Doppelfärbung eines Gefrierschnitts mit anti-alpha-SMA- und anti-CD31-

Antikörpern: A) CD31 (grün), B) alpha-SMA (rot), C) zusammengesetztes Bild mit Dapi (blau), D) stärkere Vergrößerung aus C). C, D) Blutgefäße mit alpha-SMA-positiver Tunica media (*) erscheinen durch CD31-Expression im Endothel gelblich. Blutkapillaren (Pfeile) exprimieren CD31 in höherem Maße als die schwach CD31-positiven Lymphgefäße (>). 


\section{Diskussion}

\subsection{Fragestellung}

Beim Menschen stellen Lymphangiome ca. 5\% aller benignen Tumoren des Säuglings- und Kindesalters dar (Bill und Sumner 1965; Zadvinskis et al. 1992; Charabi et al. 2000). Dabei manifestiert sich die Erkrankung in 50-60\% der Fälle bereits direkt nach der Geburt. Insgesamt können 80-90\% der Läsionen bis zum 2. Lebensjahr diagnostiziert werden. Am häufigsten manifestieren sich Lymphangiome dabei als eine asymptomatische weiche, halb-solide Masse, die zu infiltrativem Wachstum fähig ist, jedoch keine Tendenz zur malignen Entartung zeigt (Bill und Sumner 1965; Zadvinskis et al. 1992). Die endothelial ausgekleideten Räume können aus kapillären Konvoluten bis hin zu mehrere Zentimeter messenden Zysten bestehen. Das umgebende Bindegewebe ist ebenfalls von variabler Dicke und enthält neben leukozytärer Infiltration auch Rundzellen und glatte Muskelzellen (Bill und Sumner 1965). Die Lymphangiome können dabei als solitäre oder multiple, flüssigkeitsgefüllte Hohlräume imponieren und sind am häufigsten im Bereich des Nackens lokalisiert (Goetsch 1938; Potter EL und Craig 1975; Hamoir et al. 2001; Giguere et al. 2002a), was aufgrund der Nähe zu vitalen Nerven und Blutgefäßen eine vollständige chirurgische Entfernung oft verhindert und das Lymphangiom so zu einer häufig rezidivierenden Erkrankung macht (Charabi et al. 2000). Alternative Therapiekonzepte beinhalten eine Sklerosierung der Lymphgefäße beispielsweise mit Picibanil (OK-432), wodurch sich eine Reduktion des Volumens erzielen lässt (Giguere et al. 2002b). Insgesamt ist das Erscheinungsbild des Lymphangioms beim Menschen vielgestaltig. Die Klassifikation von Landing und Faber (1956) teilt die Lymphangiome daher in drei Gruppen ein. Aus dünnwandigen lymphatischen Kanälen mit kapillärem Durchmesser aufgebaute Läsionen bezeichnen sie als Lymphangioma simplex, während aus dilatierten lymphatischen Kanälen bestehende Läsionen, die häufig von einer fibrösen Tunica adventitia umgeben sind, als kavernöse Lymphangiome klassifiziert werden. Des Weiteren Klassifizieren sie das zystische Lymphangiom oder zystische Hygrom, das aus Zysten von einigen Millimetern bis hin zu mehreren Zentimetern im Durchmesser aufgebaut ist.

Zur Verbesserung bestehender Therapieverfahren als auch zur Erforschung möglicher kausaler Therapien wäre ein gutes Tiermodell von großer Bedeutung. Ein Maus-Lymphangiom-Modell wurde 1999 von Mancardi et al. vorgestellt. In meiner Arbeit habe ich daher nach Mancardi et al. (1999) experimentell, durch intraperitoneale Injektion von Freund's incomplete adjuvant (FIA), in Mäusen erzeugte Lymphangiome mit Hilfe verschiedener Antikörper untersucht und 
immunhistologisch charakterisiert. Dabei konnte ich neben den neu entstandenen Blut- und Lymphgefäßen innerhalb der Lymphangiome eine unspezifische Entzündungsreaktion auf das FIA beobachten, die bereits in den 60er Jahren nach intraperitonealen Mineralölinjektionen durch einige Forscher beschrieben worden ist. In ihrer Arbeit bezeichneten Potter M und MacCardle (1964) die von ihnen induzierten Läsionen daher als Öl-Granulome. Ich habe in meiner Arbeit sowohl die durch das FIA induzierte Gefäßproliferation, als auch die inflammatorische Reakion untersucht. Was meine Beobachtungen für die Übertragbarkeit des Tiermodells auf den Menschen bedeutet, ist ebenso Teil dieser Diskussion wie die Aussagekraft der von mir verwendeten Immunfluoreszenz-Marker zur Untersuchung der Blut- und Lymphgefäße innerhalb der experimentellen Lymphangiome.

\subsection{Immunhistologische Untersuchung der Endothelzellen des Lymphangioms}

Die Unterscheidung von Blut- und Lymphgefäßen innerhalb der Lymphangiome beziehungsweise Öl-Granulome (die Begriffe werden im Folgenden synonym verwendet) gelang mit Hilfe verschiedener Antikörper. Dabei markierte anti-Meca32 die sich neu entwickelnden Blutgefäße, die zum Zeitpunkt meiner Untersuchung stets weiter in die Tumormasse der ÖlGranulome vorgedrungen waren, als die Lyve1-positiven Lymphgefäße. Weiter habe ich beobachtet, dass das Diaphragma der Ausgangspunkt sowohl der Lymphangiognense als auch der Hämangiogenese ist, wobei die Blutgefäße den Lymphgefäßen offensichtlich als eine Art Leitstruktur dienen.

Antikörper gegen CD31 markierten sowohl Endothelzellen von Blut- als auch von Lymphgefäßen. Die Expression von CD31 ist dabei in den Blutendothelzellen signifikant höher als in den Lymphendothelzellen, eine Beobachtung, die bereits Wilting et al. (2002) bei normaler und ödematöser Haut beschrieben haben. Innerhalb der Öl-Granulome zeigten die Blutgefäße außerdem eine unterschiedliche Gefäßdifferenzierung, so dass ich in einigen Blutgefäßen eine anti-alpha-SMA-positive Tunica media identifizieren konnte. Durch Doppelfärbungen mit Antikörpern gegen alpha-SMA, dem typischen Aktin der glatten Muskelzellen (Skalli et al. 1986; Benzonana et al. 1988) und anti-CD31 ließen sich verschiedene Gefäßtypen innerhalb der ÖlGranulome charakterisieren. Dabei können Gefäße, die sowohl alpha-SMA als auch CD31 exprimieren, dem arteriellen oder venösen Blutgefäßsystem zugeordnet werden, während es sich 
bei stark anti-CD31-positiven, anti-alpha-SMA-negativen Gefäßen um Blutgefäßkapillaren und bei schwach anti-CD31-positiven, anti-alpha-SMA-negativen Gefäßen um Lymphgefäße handelt.

Podoplanin, das von Podozyten, Keratinozyten und Lymphendothelzellen stark exprimiert wird (Schacht et al. 2003) und beim Menschen auch in Osteoblasten und Pneumozyten Typ 1 vorkommt (Wetterwald et al. 1996), zeigte zusätzlich zu den Lyve1-positiven Lymphendothelzellen auch ein Signal in Epithelzellen des Peritoneums und der Pleura parietalis, was vermuten lässt, dass anti-Podoplanin-Antikörper in Öl-Granulomen nicht Lymphendothelspezifisch genug sind, um alleine, ohne anti-Lyve1, als Marker eingesetzt werden zu können. Makinen et al. (2001b) berichten zudem von Lymphendothelzellkulturen, in denen sie nur in einem Teil der anti-Podoplanin-positiven Endothelzellen auch Lyve1-Expression fanden. Somit kann auch die Lyve1-Expression variabel sein. In meinen eigenen Untersuchungen habe ich jedoch immer eine starke Lyve1-Expression in den Lymphgefäßen der Öl-Granulome gesehen und den lymphendothelialen Charakter der Gefäße mit anti-Prox1 bestätigen können.

\subsection{Das experimentelle Lymphangiom der Maus nach Mancardi et al. (1999)}

Vor einigen Jahren etablierten Mancardi et al. (1999) durch ihre Arbeit an adulten Mäusen, denen sie Freund's incomplete adjuvant (FIA) intraperitoneal injizierten, ein experimentelles Mauslymphangiom-Modell. Mancardis Untersuchung der benignen Tumoren ergab, dass diese vorwiegend aus Endothelzellen aufgebaut waren, welche die Endothelmarker CD31/PECAM-1, CD54/ICAM-1, CD102/ICAM-2 sowie den Wachstumsfaktorrezeptor VEGFR-2 exprimierten. Mancardis Beobachtungen beruhten dabei im Wesentlichen auf Untersuchungen mittels in situ Hybridisierung, welche sich in den von mir durchgeführten Untersuchungen mit monoklonalen Antikörpern nicht vollständig replizieren ließen.

Im Gegensatz zu den Ergebnissen von Mancardi et al. (1999) konnte ich im Rahmen meiner Arbeit die Expression von VEGFR-2 nur in Blutendothelzellen beobachten und nicht in Lymphendothezellen. Die blutendothelzellspezifischen Rezeptoren Tie-1 und Tie-2 sowie der im hohen Maße lymphendothelspezifische Rezeptor VEGFR-3 konnten von Mancardi et al. (1999) durch in situ Hybridisierung in den Gefäßen nachgewiesen werden. Mein Versuch, VEGFR-3 mit Hilfe von zwei verschiedenen monoklonalen Antikörpern nachzuweisen, erbrachte kein 
zuverlässiges Ergebnis. Die verwendeten Antikörper markierten Blutgefäße, aber keine Lymphgefäße.

In vitro konnten Mancardi et al. (1999) Zellen aus den Tumoren isolieren und vermehren. Diese differenzierten spontan zu gefäßartigen Strukturen aus. Innerhalb der Tumoren zeigten die Endothelzellen verschiedene Phasen der vaskulären Entwicklung. In ihren elektronenmikroskopischen Untersuchungen beobachteten Mancardi et al. (1999) gefäßartige Strukturen mit Lumina, die zum Teil von einer einzigen Endothelzelle begrenzt wurden. Mancardi et al. (1999) gaben an, dass die Tumoren eine geeignete und leicht reproduzierbare Quelle zur Gewinnung von Lymphendothelzellen darstellen. Weiterhin hielten sie es für möglich, dass das von ihnen entwickelte Mauslymphangiom als Modell für die beim Menschen auftretenden Erkrankungen des Lymphgefäßsystems dienen könnte. Dieser Überlegung sind auch Short et al. (2007) in ihrer Arbeit nachgegangen. Wie von Mancardi et al. (1999) beschrieben, wurde von Short et al. (2007) durch intraperitoneale Injektionen von FIA in Ratten lymphatisch malformiertes Gewebe induziert und mit immunhistologischen Markern, sowie mit Ultraschall und MRT untersucht. Zusätzlich injizierten Short et al. (2007) einer Gruppe von Versuchstieren das FIA im Bereich des Nackens und beobachteten, dass sich hier die gleichen Läsionen entwickelten, wie intraperitoneal. Makroskopisch imponierten die intraperitonealen Läsionen als weißliche dem Peritoneum anhaftende Plaques, welche histopathologisch zahlreiche Zysten enthielten, die von einer einzelnen Endothelzellschicht ausgekleidet waren.

Immunhistologische Färbungen zeigten die Expression des Pan-Endothelmarkers CD31 sowie der lymphendothelspezifischen Marker VEGFR-3 und Prox1. Meine Untersuchungen haben ergeben, dass die zystischen Räume innerhalb des Öl-Granuloms sowohl von Zellen, die antiLyve1-und anti-Podoplanin-positiv sind ausgekleidet sein können, als auch von Zellen, die nur Podoplanin-positiv aber Lyve1-negativ sind. Eine mögliche Erklärung hierfür liefert die Beobachtung, dass Podoplanin auch von Epithelzellen der Pleura und des Peritoneums exprimiert wird und es bei der Entstehung des Öl-Granuloms möglicherweise zur Verschleppung von Serosazellen in das Öl-Granulom kommt. An den Injektionsstellen im Nacken beobachteten Short et al. (2007) sonographisch mikro- und makrozystische Malformationen. Im MRT konnten ebenfalls flüssigkeitsgefüllte Zysten nachgewiesen werden, immunhistologisch ließ sich auch hier die Expression von CD31, VEGFR-3 und Prox1 nachweisen. Short et al. (2007) interpretierten die Formation der Läsionen als Resultat einer Stimulation des Lymphsystems im Bereich der Injektion zur Dränage des FIA. Das Mausmodell bewerteten sie dabei ähnlich wie Mancardi et al. 
(1999) als nützlich für die Erforschung von Therapieverfahren zur Behandlung von Lymphangiomen beim Menschen, sowie der Lymphangiogenese.

Hier muss noch einmal angemerkt werden, dass das Verfahren intraperitonealer Öl-Injektionen bereits in den 60er Jahren durch eine Reihe von Forschern auf der Suche nach einem geeigneten Tiermodell für Plasmazelltumoren beschrieben worden ist. Die histologischen Untersuchungen der intraperitonealen Läsionen zeigten damals, dass es sich bei den Tumoren in erster Linie um Zellen des Immunsystems handelt. In ihrer Arbeit bezeichneten Potter M und MacCardle (1964) die von ihnen induzierten Läsionen daher als Öl-Granulome.

\subsection{Freund's incomplete adjuvant (FIA)}

Freundsches Adjuvans ist eine Wasser in Öl Emulsion bestehend aus einem nicht metabolisierbaren Öl, einem Surfactant und hitzeabgetöteten Mykobakterien (Freund et al. 1949; Freund 1951). Das unvollständige Adjuvans (FIA) enthält keine Mykobakterien (Humphrey and White 1964; Merrill 1976; Broderson 1989) und wird zur Steigerung der Antikörperproduktion gegen Antigene verwendet, die zusammen mit dem Adjuvans injiziert werden. Die Wirkung beruht dabei auf der Induktion einer inflammatorischen Reaktion, welche zu zellulären Interaktionen mit dem injizierten Antigen führt (Borek 1977, Broderson 1989).

\subsection{Subkutane Injektionen von FIA und Mineralölen bei Mäusen}

Schon vor 70 Jahren untersuchten Pullinger und Florey (1937) Abszesse in den Ohren von Mäusen, die sie durch Injektion von Terpentin und Amorphous silica, einem natürlich vorkommenden Siliziumoxid $\left(\mathrm{SiO}_{2}\right)$, das keine kristallinen Strukturen bildet, induziert hatten. Ziel ihrer Untersuchung war es herauszufinden, ob sich durch die verschiedenen Stimuli Unterschiede in der proliferativen Antwort der Lymphgefäße detektieren ließen, da Terpentin eine akute Entzündung verursacht, während Amorphous silica ein chronisch-inflammatorisches Geschehen herbeiführt. Die durch Terpentininjektion induzierten Abszesse führten dabei zu einer starken Proliferation von Lymphgefäßen, die nach Abheilung des Abszesses keine komplette Regression zeigten. Pullinger und Florey folgerten daraus, dass Lymphkapillaren durch akute Inflammation in der Haut zur Proliferation angeregt werden. Ähnliches beobachteten sie bei den Versuchstieren, denen Amorphous silica injiziert worden war, wo sich durch 
Farbinjektionen ein persistierender lymphatischer Plexus darstellte, dessen Netzwerk aus Lymphkapillaren extrem dicht war. Des Weiteren fanden Pulliner und Florey (1937) zahlreiche polymorphkernige Leukozyten, Lymphozyten, Fibroblasten und Makrophagen innerhalb der Läsion.

1961 veröffentlichte Dale, die wie Pullinger und Florey (1937) Injektionen an Mäuseohren vornahm, eine Untersuchung über die Effekte der einzelnen Komponenten des FIA. Im Fokus stand die Frage, inwiefern die einzelnen Komponenten des Adjuvans die Proliferation von Lymphgefäßen stimulieren. Dale (1961) beobachtete, dass sich durch Injektion von FIA eine markante Proliferation von Lymphgefäßen auslösen ließ, während die alleinige Injektion des Öls (Bayol F) oder des Surfactant (Arlacel A) geringere Proliferation verursachte. Die Injektion einer Suspension von abgestorbenen M. tuberculosis führte zu keiner Neubildung von Lymphgefäßen. Wurden die Mykobakterien aber zusammen mit FIA injiziert, zeigte sich die insgesamt stärkste Proliferationsantwort. Eine frühere Arbeit von Dale (1960) vergleicht die Effekte von Terpentin Injektionen wiederum in Mäuseohren mit denen des Freundschen Adjuvans. Darin beschreibt Dale (1960) die durch Terpentin ausgelöste Proliferation von Lymphgefäßen als diffus, während das Freundsche Adjuvans ein dichtes Netzwerk von Lymphgefäßen in einem umschriebenen Bereich herbeiführt.

\subsection{Intraperitoneale Injektionen von FIA und Mineralölen bei Mäusen}

Die Untersuchung der Effekte von intraperitonealen Injektionen des FIA und einer Reihe von Paraffin- und Mineralölen begannen in den 1960er Jahren. Die hierbei induzierten Tumoren wurden im Allgemeinen als Öl-Granulome beschrieben. Dabei konnte beobachtet werden, dass sich innerhalb der Öl-Granulome in Abhängigkeit von dem verwendeten Öl nach einiger Zeit Plasmazelltumoren entwickelten. Außerdem zeigte sich, dass BALB/c-Mäuse für die Entwicklung von Plasmozytomen weit anfälliger waren als andere Mausstämme (Merwin und Redmon 1963; Yamada H et al. 1969; Potter M 1972). Die zelluläre Zusammensetzung und die Genese der Öl-Granulome wurden in zahlreichen Arbeiten histologisch untersucht (Potter M und Robertson 1960; Potter M und Boyce 1962; Potter M und MacCardle 1964; Slawa 1980; Janz et al. 1987). BALB/c-Mäuse, denen FIA zusammen mit hitzeabgetöteten Staphylokokken 
intraperitoneal injiziert wurde, entwickelten innerhalb weniger Tage lipogranulomatöse Läsionen, welche dem Peritoneum anhafteten und aus vielen zystenähnlichen Räumen und reaktivem Bindegewebe bestanden. Die Untersuchung der Zysten ergab, dass sie Paraffinöl enthielten. Ihre Wände waren zum Teil dünn, möglicherweise endothelial begrenzt, während andere mit epitheloiden Zellen, Histiozyten und Granulozyten ausgekleidet waren (Potter M und Robertson 1960; Potter M und Boyce 1962). Bei der intraperitonealen Injektion der Öl Komponente (Bayol F) des Freundschen Adjuvans wurde submesothelial die Entwicklung von Öl-Granulomen beobachtet, die sich als weißlich milchiges Gewebe darstellten und typischerweise einen nodulären Charakter aufwiesen. Die Granulome resultierten aus der extensiven Inkorporation von Öl in das submesotheliale Bindegewebe. Histologisch wurden in frühen Stadien Öltropfen gesehen, die von Makrophagen umgeben dem Mesothel anhafteten und später zusammen mit den Makrophagen vom Mesothel umschlossen wurden. Zusätzlich wurden Regionen beobachtet, in denen die sich entwickelnden Granulome kein Mesothel an der Oberfläche aufwiesen. Die Vaskularisation der Öl-Granulome war dicht mit Charakteristika neu entstandener Gefäße. Innerhalb der Öl-Granulome wurden neben undifferenzierten mesenchymalen Zellen auch Fibroblasten, Lymphozyten, Plasmazellen und Granulozyten gefunden (Potter M und MacCardle 1964).

Slawa (1980) berichtet ebenfalls von der Entstehung vieler inflammatorischer Öl-Granulome auf dem Peritoneum von BALB/c-Mäusen, denen er Bayol F intraperitoneal injiziert hatte. In der histologischen Untersuchung beobachtete er neben Öl beladenen Zellen, Plasmozyten und Makrophagen. 57\% der BALB/c-Mäuse entwickelten im weiteren Verlauf ein Plasmozytom, dabei war Aszites das makroskopisch führende Symptom. Janz et al. (1987), die Paraffinöl intraperitoneal injizierten, kamen zu ähnlichen Ergebnissen. Ihre histopathologischen Untersuchungen zeigten, dass die peritonealen Öl-Granulome die Grundlage von Plasmazelltumoren waren und dass Aszites ein Anzeichen für die Entstehung der Tumoren war.

Verschiedene Untersuchungen an immunsupprimierten BALB/c-Mäusen ergaben, dass sich die Entstehung von Öl-Granulomen und damit auch von Plasmazelltumoren durch Immunsuppression verhindern lässt (Takakura et al. 1966; Potter M et al. 1985; McDonald und Degrassi 1992; Avcu et al. 2005). Takakura et al. (1966) beobachteten, dass sich bei BALB/cMäusen, die durch Cortisol immunsupprimiert wurden, keine Plasmazelltumoren induzieren ließen. Der inflammatorische Prozess wurde vollständig unterdrückt, so dass sich auch keine nodulären Öl-Granulome entwickelten. Das Mineralöl blieb frei in der Peritonealhöhle, lediglich 
kleine stecknadelkopfgroße granulomatöse Läsionen wurden vereinzelt beobachtet, während die Versuchstiere der Kontrollgruppe im Anschluss an die intraperitoneale Mineralölinjektion (Prime Oil 355) innerhalb von Wochen milchig weiße Granulomknoten auf der mesothelialen Oberfläche entwickelten. Nach Injektion stieg die Zahl der inflammatorischen Zellen in der peritonealen Flüssigkeit rasch an. In der Anfangsphase handelte es sich dabei hauptsächlich um lymphoide und neutrophile Zellen. Die Zahl der Makrophagen stieg dann innerhalb der ersten Woche so rapide an, dass sie zur häufigsten Zellpopulation (43,8\%) wurden und die der Lymphozyten zur zweit häufigsten (28\%). Takakura et al. (1966) berichteten, dass 88\% der Mäuse 12 Monate nach Injektion Plasmazelltumoren entwickelt hatten.

Aufgrund des Fehlens der geeigneten Technik zur damaligen Zeit, wurden die Öl-Granulome in keiner der beschrieben Arbeiten immunhistologisch untersucht.

\subsection{Phagozytäre Reaktionen nach intraperitonealer Ö1-Injektion}

Sowohl Pullinger und Florey (1937), als auch Potter M und MacCardle (1964), Slawa (1980) und Takakura et al. (1966) beobachteten zahlreiche inflammatorische Zellen in den von ihnen induzierten Öl-Granulomen. Makrophagen wurden dabei in jeder dieser Arbeiten gefunden. Takakura et al. (1966) beschreiben sie neben den Lymphozyten sogar als häufigste Zellpopulation in der peritonealen Flüssigkeit. Biewenga et al. (1995) vermuteten, dass Makrophagen, die 70-90\% der frei in der Peritonealhöhle vorkommenden Zellen in Mensch und Labortier ausmachen (Bos et al. 1988; Plasman und Vray 1993), möglicherweise die Hauptrolle beim Prozessieren und Transportieren von injiziertem Fremdmaterial besitzen. Ihre Untersuchung ergab, dass Mäuse, bei denen zuvor durch Dichlormethylenbisphosphonate die gesamte intraperitoneale Makrophagenpopulation eliminiert worden war, eine beschleunigte Repopulation des Omentum mit Makrophagen zeigten, wenn FIA intraperitoneal injiziert wurde. Auch Delemarre et al. (1990) beobachteten eine Beeinflussung der Repopulation der Peritonealhöhle mit Makrophagen durch FIA. Die Arbeit von Deams und Koerten (1978), die die zelluläre Zusammensetzung des peritonealen Exsudats nach intraperitonealer Injektion von Paraffinöl bei Mäusen untersuchten, ergab dass der Hauptunterschied zwischen der Kontroll- und der Experimentalgruppe ein Wechsel der Zellzahl ist, verursacht durch einen Anstieg von neutrophilen Granulozyten und Makrophagen in der Peritonealhöhle. Ähnliches beobachteten auch Alfonso et al. (1998). 
Der Anstieg der Gesamtzahl der Makrophagen resultierte dabei aus der Exsudation von Monozyten aus dem Blut (van Furth 1976). Demnach können intraperitoneal zwei Arten von Makrophagen unterschieden werden (Deams et al. 1975; Deams et al. 1976), nämlich residente Makrophagen (Deams und Brederoo 1973) und solche, die von Monozyten aus dem Blut abstammen (van Furth und Cohn 1968; van Furth 1976). Die Makrophagenpopulation beim inflammatorischen Geschehen besteht also aus lokal vorhandenen Makrophagen als auch aus exsudierten Monozyten (Deams und Koerten 1978).

\subsection{Das inflammatorische Geschehen und seine Bedeutung für die Häm- und Lymphangiogenese}

Meine immunhistologischen Färbungen mit Antikörpern gegen CD45, einem Glykoprotein, das auf den Zellmembranen aller leukozytärer Zellen vorkommt, zeigen, dass die FIA induzierten Tumoren vornehmlich aus Leukozyten bestehen. CD45, das bei der Signaltransduktion von Immunzellen als rezeptoranaloge Protein-Thyrosin-Phosphatase (PTP) regulatorische Aufgaben besitzt (Thomas 1989; Trowbridge und Thomas 1994; Hermiston et al. 2003), wird ausschließlich von Zellen des hämatopoetischen Systems exprimiert (Trowbridge 1978; Standring et al. 1978; Sunderland et al. 1979; Hoessli und Vassalli 1980; Dalchau et al. 1980). Sowohl die Hämangiogenese als auch die Lymphangiogenese, die ich beobachten konnte, scheinen dabei sekundär von den Leukozyten induziert zu sein. Die Gefäßsprossungen gehen dabei von benachbarten Organen z.B. dem Diaphragma aus. Am Anfang steht offensichtlich das inflammatorische Geschehen, das durch die immunhistologische Färbung mit anti-CD45Antikörpern sichtbar gemacht werden kann. In ihren frühen Arbeiten beobachteten Pullinger und Florey (1937), Potter M und MacCardle (1964), Slawa (1980) und Takakura et al. (1966) ebenfalls zahlreiche inflammatorische Zellen. Potter M und MacCardle (1964) berichten, dass in entstehenden Öl-Granulomen Öl-Tropfen von Makrophagen phagozytiert werden. Biewenga et al. (1995) vermuteten, dass Makrophagen möglicherweise die Hauptrolle beim Prozessieren und Transportieren von injiziertem Fremdmaterial besitzen. In zahlreichen Untersuchungen konnte gezeigt werden, dass Makrophagen auch in der Lage sind, den hämangiogenen Wachstumsfaktor VEGF-A (Berse et al. 1992; Fava et al. 1994) und die lymphangiogenen Wachsumsfaktoren VEGF-C und VEGF-D (Sunderkotter et al. 1994; Skobe 2001; Schoppmann 2002; Baluk et al. 2005) zu exprimieren. Taichman et al. (1997) konnten VEGF-A-Expression in neutrophilen Granulozyten in inflammatorischen Geweben beobachteten. Baluk et al. (2005) zeigten, dass 
neben Makrophagen auch neutrophile Granulozyten und Epithelzellen in der Lage sind, VEGF$\mathrm{C}$ und VEGF-D zu exprimieren. Im Tiermodell einer chronisch-inflammatorischen Atemwegsinfektionen mit Mycoplasma pulmonis beobachteten diese Autoren auch, dass VEGF-Cund VEGF-D-exprimierende Immunzellen in der Lage sind, Lymphangiogenese auszulösen. Bereits Koch AE et al. (1986) zeigten, das aktivierte Monozyten und Makrophagen in der Lage sind, Angiogenese in die gefäßfreien Kornea hinein zu induzieren. In einem ähnlichen Tiermodell konnten Cursiefen et al. (2004) die Lymphangiogenese sowohl durch VEGF-A-Inhibitoren als auch durch die Eliminierung der VEGF-C- und D-produzierenden Makrophagen blockieren. Es ist also anzunehmen, dass innerhalb der Öl-Granulome Wachstumssignale für Hämangiogenese und Lymphangiogenese von CD45-positiven Leukozyten ausgehen.

\subsection{Rolle der VEGF-Rezeptoren bei der Häm- und Lymphangiogenese}

Das Zusammenspiel von VEGF-C und VEGF-D bei der Induktion von Lymphangiogenese und Hämangiogenese wurde bereits in zahlreichen Untersuchungen gezeigt (Oh et al. 1997; Jeltsch et al. 1997; Kubo et al. 2002; Veikkola et al. 2001). Bei der Lymphangiogenese wirken VEGF-C und VEGF-D dabei vorwiegend über die Aktivierung von VEGFR-3 (Joukov et al. 1996; Lee J et al. 1996; Orlandini et al. 1996; Yamada Y et al. 1997; Achen et al. 1998), dessen Expression in adulten Geweben in hohem Maße lymphendothelspezifisch ist (Kaipainen et al. 1995; Partanen et al. 2000). Baldwin et al. (2001) konnten zeigten, dass VEGF-D in Mäusen, anders als beim Menschen, ausschließlich an VEGFR-3 bindet, während es beim Menschen zusätzlich ein Ligand von VEGFR-2 ist. Der Verlust von VEGF-D führt aber bei Knock-out-Mäusen zu keinen sichtbaren Effekten (Baldwin et al. 2005). Nach enzymatischer Spaltung in vivo nimmt die Affinität von VEGF-C und VEGF-D zum VEGFR-2 stetig zu. Damit steigt die Fähigkeit zusätzlich zur Lymphangiogenese auch Hämangiogenese via VEGFR-2 zu induzieren (Joukov et al. 1997; Cao et al. 1998; Stacker et al. 1999). VEGFR-2 wird in hohem Maße auf Blutendothelzellen exprimiert (Kriehuber et al. 2001; Nagy et al. 2002). In mehreren Untersuchungen konnte jedoch gezeigt werden, dass VEGFR-2, der sowohl durch VEGF-C und VEGF-D als auch durch VEGF-A aktiviert werden kann, auch von Lymphendothelzellen exprimiert wird (Wilting et al. 1997; Kriehuber et al. 2001; Veikkola et al. 2001; Nagy et al. 2002; Hirakawa et al. 2003; Hong et al. 2004). Tumorassoziierte als auch wundassoziierte Blutendothelzellen können auch die Fähigkeit erlangen, VEGFR-3 zu reexprimieren (Partanen et 
al. 1999; Kubo et al. 2000). Da VEGF-C und VEGF-D nach enzymatischer Spaltung auch als Liganden von VEGFR-2 zur Verfügung stehen und da VEGFR-2 ebenfalls von Lymphendothelzellen exprimiert wird (Veikkola et al. 2001; Hong et al. 2004), ist eine exakte Gewichtung der Funktionen von VEGFR-2 gegenüber VEGFR-3 bei der Lymphangiogenese kaum möglich. Veikkola et al. (2001) beobachteten jedoch, dass die alleinige Aktivierung der VEGFR-3 Signaltransduktion zum Auslösen der Lymphangiogenese bei Mäusen ausreichend ist.

Meine eigenen Untersuchungen zeigen, dass innerhalb der Öl-Granulome VEGFR-2 ausschließlich von Blutendothelzellen exprimiert wird. Das Lymphendothel, das mit Hilfe der Lymphendothelmarker Lyve1 und Prox1 sicher dargestellt werden konnte, zeigte keine Doppelpositivität von Lyve1 und VEGFR-2 in den Immunfluoreszenzfärbungen. Somit stellt sich die Frage, ob die untersuchten Mauslymphangiome tatsächlich ein dem Menschen vergleichbares Untersuchungsmodell darstellen, da sie sich nachgewiesenermaßen in ihrer VEGFR-2-Expression deutlich vom humanen Lymphangiom unterscheiden.

\subsection{Einfluss der Blutendothelzellen auf die Lymphangiogenese}

Bereits Clark und Clark (1932) beobachteten, dass in adulten Versuchstieren die Lymphangiogenese in Wunden von bereits existierenden Lymphgefäßen ausgeht. Nach Folkman (1995) ist die Angiogenese, das Auswachsen von neuen Blutgefäßen aus bereits bestehenden Gefäßen ein wichtiger Aspekt chronisch-inflammatorischer Erkrankungen. So kann auch für meine Experimente vermutet werden, dass die vom Diaphragma ausgehende Hämangiogenese, wie auch die Lymphangiogenese ihren Ursprung in dort bereits existierenden Blutgefäßen bzw. Lymphgefäßen hat. Deutlich zu sehen war auch, dass die Hämangiogenese innerhalb des Öl-Granuloms der Lymphangiogenese vorausging, wobei die Blutgefäße stets tiefer in den Tumoren zu finden waren als die Lymphgefäße, denen sie als eine Art Leitstruktur zu dienen schienen. Eine mögliche Erklärung hierfür liefern Untersuchungen von Kriehuber et al. (2001) und Makinen et al. (2001a), die zeigen konnten, dass das Wachstum von Lymphendothelzellen in Kultur VEGF-C-abhängig erfolgt und dass in gemischten Zellkulturen VEGF-C von Blutendothelzellen bereitgestellt wird. VEGF-C-Expression durch Blutendothelzellen ist ebenfalls in einer Reihe weiterer Untersuchungen nachgewiesen worden Joukov et al. 1996; Hirakawa et al. 2003; Baluk et al. 2005). Papoutsi et al. (2000) beobachteten in ihrer Arbeit an experimentellen Melanomen, dass diese durch VEGF-C-Produktion in der Lage 
waren Lymphangiogenese zu induzieren. Die Transfektion der Melanomzellen mit sflt4 (lösliche Form des VEGFR-3) kodierender cDNS, zeigte in ihren Untersuchungen eine weitgehende aber nicht vollständige Inhibition der Lymphangiogenese, während die Hämangiogenese völlig unbeeinträchtigt blieb.

\subsection{Hypothese über die Genese der Ö1-Granulome}

Die immunhistologischen Färbungen mit anti-CD45-Antikörpern haben gezeigt, dass das FIA zu einer chronisch-inflammatorischen Reaktion auf dem Peritoneum führt, und die histologischen Untersuchungen von Potter M und MacCardle (1964) lassen vermuten, dass sowohl in der Peritonealhöhle residente Makrophagen, als auch aus dem Blut rekrutierte Monozyten zur Eliminierung des Fremdmaterials durch Phagozytose herangezogen werden (Deams und Koerten 1978; Delemarre et al. 1990; Biewenga et al. 1995). Dabei scheint sich aus den zahlreichen Untersuchungen mit Öl-Injektionen (Pullinger und Florey 1937; Dale 1960, 1961; Potter M und Robertson 1960; Potter M und Boyce 1962; Potter M und MacCardle 1964; Slawa 1980; Janz et al. 1987) die Regel ableiten zu lassen, dass je wasserunlöslicher das Adjuvans ist, desto länger ist seine Persistenz innerhalb der Peritonealhöhle. Damit verstärkt sich der von ihm ausgehende inflammatorische Stimulus. Die zum Teil makroskopisch sichtbaren Zysten der Öl-Granulome enthalten das Adjuvans (Potter M und Robertson 1960; Potter M und Boyce 1962; Short et al. 2007). Die Entstehung der Granulome kann demnach auch als Folge erschwerter oder unmöglicher Metabolisierung des Adjuvans interpretiert werden, wodurch es zu einer Anreicherung von Makrophagen und anderer Phagozyten entlang des Peritoneums kommt. Weil die Metabolisierung nicht gelingt, kommt es zur Ausbildung von Granulomen, in denen das Adjuvans in Phagozyten eingelagert wird, um es gegen die Peritonealhöhle abzuschirmen.

Da aktivierte Makrophagen und andere Leukozyten in der Lage sind VEGF-A, VEGF-C und VEGF-D zu exprimieren (Berse et al. 1992; Fava et al. 1994; Sunderkotter et al. 1994; Skobe 2001; Schoppmann 2002; Baluk et al. 2005), lässt sich auf diese Weise ein Teil der beobachteten Hämangiogenese und Lymphangiogenese erklären. Auch angiogene Blutendothelzellen sind in der Lage, VEGF-C zu exprimieren (Joukov et al. 1996; Kriehuber et al. 2001; Makinen et al. 2001a; Hirakawa et al. 2003; Baluk et al. 2005), wodurch die Blutgefäße, wie von mir beobachtet, den Lymphgefäßen vorangehen und vermutlich als eine Art Leitstruktur dienen. 


\subsection{Bewertung der Übertragbarkeit des Tiermodells auf den Menschen}

Unter der Annahme, dass Zellen des Immunsystems maßgeblich für die Genese der experimentellen Lymphangiome verantwortlich sind, scheint das Heranziehen dieses Tiermodells für die Erforschung neuer Therapien zur Behandlung von Lymphangiomen beim Menschen weniger geeignet zu sein. Auch wenn die Pathogenese der menschlichen Lymphangiome bis heute nicht eindeutig geklärt ist, so unterscheidet sie sich doch grundlegend vom Tiermodell in folgenden Punkten: Von einigen Autoren wird die Ursache für die Entstehung der Lymphangiome beim Menschen in der fehlenden Dränage von Lymphe aus den (primordialen) Lymphsäcken des Embryos in das venöse System angesehen. Sekundär kommt es so zu einer Vergrößerung von obliterierten lymphatischen Kanälen, aus denen sich Zysten entwickeln können (Smith 1982; Giguere et al. 2002a; Koch BL 2005; Lee BB et al. 2005). Andere Autoren gehen von einer abnormalen Abkapselung der (primordialen) Lymphsäcke in der frühen Embryogenese als Ursache aus (Goetsch 1938; Philips und McGahan 1981). Eine weitere Theorie macht den Verlust der Verbindung von aberrierenden Lymphgefäßanlagen zu den embryonalen Lymphsäcken für die Entstehung der mit Lymphe gefüllten Zysten verantwortlich (Lee K und Klein 1980). Weitere mögliche Ursachen werden in einer Hyperproliferation von Lymphendothelzellen durch überschießende Expression lymphendothelialer Wachstumsfaktoren oder aber einem Mangel an deren Inhibitoren gesehen (Albuquerque et al. 2009).

Mit Hilfe von Immunsuppressiva (Takakura et al. 1966; Potter M et al. 1985; McDonald und Degrassi 1992; Avcu et al. 2005) konnte gezeigt werden, dass sich die Entstehung von Öl-Granulomen bei der Maus vollständig verhindern lässt. Im Gegensatz dazu ist zu vermuten, dass menschliche Lymphangiome nicht primär durch Inflammation, sondern vielmehr durch primäre Gendefekte der Lymphendothelzellen hervorgerufen werden (Charabi et al. 2000; Hamoir et al. 2001; Koch BL 2005). Singh und Carr (1966) beobachteten außerdem, dass das zystische Hygrom besonders häufig in Aborten vorkommt, die den Karyotyp 45,X0 (Turnersyndrom) aufweisen. Die Tatsache, dass auch in menschlichen Lymphangiomen Inflammation beobachtet werden kann (Perkes et al. 1979; Frigoletto et al. 1980; Nussinovitch et al. 2001), kann als sekundäre Folge oder Komplikation des behinderten Lymphabflusses interpretiert werden, der mit Stase- und Ödembildung einhergeht. Lymphangiome des Menschen sind offensichtlich kongenitale Erkrankungen und nicht auf einen persistenten inflammatorischen 
Stimulus zurückzuführen (Charabi et al. 2000; Hamoir et al. 2001; Koch BL 2005). Hierin liegt einer der Hauptunterschiede und es bleibt abzuwarten, ob sich Therapiemethoden aus einem Tiermodell ableiten lassen, in dem der chronisch-inflammatorische Stimulus durch das FIA als Signal zur Häm- und Lymphangiogenese betrachtet werden kann. 


\section{Zusammenfassung}

Mittels intraperitonealer Injektionen von Freund's incomplete adjuvant (FIA) in adulte Mäuse, nach Mancardi et al. (1999), wurden experimentelle Lymphangiome induziert, die als weißliche Tumoren dem Diaphragma aufgelagert waren. Mittels des Cluster of Differentiation Molecule 45 (CD45), einem immunhistologischen Marker für Leukozyten, konnte ich nachweisen, dass das Tumorgewebe in erster Linie aus einer massiven Ansammlung von Leukozyten bestand. Mit Hilfe spezifischer Antikörper gegen Lymphatic Vascular Endothelial Hyaluron Receptor-1 (Lyve1) und Prospero-related Homeoboxgen-1 (Prox1) für Lymphendothelzellen sowie gegen Podoplanin, Mouse endothelial cell antigen 32 (Meca32) und Vascular Endothelial Growth Factor Receptor- 2 (VEGFR-2), ein vaskulärer Wachstumsfaktorrezeptor, wurde die Häm- und Lymphangiogenese untersucht. Dabei zeigte sich, dass Blut- und Lymphgefäße kontinuierlich vom Diaphragma ausgehend in die Tumoren vorgedrungen waren. VEGFR-2-positive Blutgefäße, welche sich mit anti-Meca32-Antikörpern und dem Pan-Endothelmarker Cluster of Differentiation Molecule 31(CD31) darstellen ließen, waren weiter in das Tumorgewebe vorgedrungen als die Lymphgefäße, die offensichtlich dem Weg der Blutgefäße folgten. VEGFR2-Expression konnte ich in den neu entstandenen Gefäßen ausschließlich in Blutendothelzellen beobachten und nicht in Lyve1- oder Prox1-positiven Lymphendothelzellen. Podoplanin wurde sowohl von Lyve1-positiven Lymphendothelzellen als auch von Lyve1-negativen Epithelzellen des Peritoneums und der Pleura parietalis exprimiert, so dass der alleinige Einsatz von Podoplanin die Lymphendothelzellen nicht eindeutig charakterisiert.

Die Bezeichnung der durch FIA verursachten Läsion als experimentelles Lymphangiom muss daher kritisch betrachtet werden. Potter M und MacCardle (1964) beschrieben die von ihnen durch Öl-Injektionen induzierten Tumoren als Öl-Granulome, eine Beschreibung, die aufgrund der massiven Infiltration des Tumors mit CD45-positiven Leukozyten zutreffender zu sein scheint. Dennoch hat sich das von Mancardi et al. (1999) beschriebene Tiermodell als Verfahren bei der Gewinnung lymphendothelialer Zelllinien bewährt. Ob dieses Tiermodell der experimentellen Lymphangiome jedoch auch auf den Menschen übertragbar ist und hier bei der Entwicklung neuer Therapien helfen kann, bleibt abzuwarten. Ähnlichkeiten zwischen Lymphangiomen des Menschen, die ca. 5\% aller benignen Tumoren des Kindes- und Säuglingsalters ausmachen, und experimentellen Lymphangiomen der Maus bestehen in der lymphendothelialen Auskleidung und der zystischen Morphologie der Läsionen. Andererseits bestehen Unterschiede in der Pathogenese. Während es sich beim menschlichen Lymphangiom um eine kongenitale Erkrankung des Lymphgefäßsystems handelt, ist im Tiermodell die Ursache in einer chronisch inflammatorisch bedingten Lymphangiogenese zu sehen. 


\section{Literaturverzeichnis}

Achen MG, Jeltsch M, Kukk E, Makinen T, Vitali A, Wilks AF, Alitalo K, Stacker SA (1998): Vascular endothelial growth factor D (VEGF-D) is a ligand for the tyrosine kinase VEGF receptor 2 (Flk1) and VEGF receptor 3 (Flt4). Proc Natl Acad Sci USA 95, 548-553

Afonso A, Lousada S, Silva J, Ellis A, Silva MT (1998) Neutrophil and macrophage response to inflamation in the peritoneal cavity of rainbow trout Oncorhynchus mykiss. A light and electron microscopic cytochemical study. Dis Aquat Org $\underline{34}$, 27-37

Albelda SM, Oliver PD, Romer LH, Buck CA (1990): EndoCAM: a novel endothelial cell-cell adhesions molecule. J Cell Biol 110, 1227-1237

Albuquerque RJ, Hayashi T, Cho WG, Kleinman ME, Dridi S, Takeda A, Baffi JZ, Yamada K, Kaneko H, Green MG, Chappell J, et al. (2009): Alternatively spliced vascular endothelial growth factor receptor-2 is an essential endogenous inhibitor of lymphatic vessel growth. Nat Med 15(9), $1023-1030$

Alqahtani A, Nguyen LT, Flageole H, Shaw K, Laberge JM (1999): 25 years' experience with lymphangiomas in children. J Pediatr Surg $\underline{34}, 1164-1168$

Avcu F, Ural AU, Yilmaz MI, Ozcan A, Ide T, Kurt B, Yalcin A (2005): The bisphosphonate zoledronic acid inhibits the developement of plasmacytoma inducted in BALB/c mice by intraperitoneal injections of pristane. Eur J Haematol $\underline{74}$, 496-500

Ayalon O, Sabanai H, Lampugnani MG, Dejana E, Geiger B (1994): Spatial and temporal relationships between cadherins and PECAM-1 in cell-cell junctions of human endothelial cells. J Cell Biol 126, 247-258

Baldwin ME, Catimel B, Nice EC, Roufail S, Hall NE, Stenvers KL, Karkkainen MJ, Alitalo K, Stacker SA, Achen MG (2001): The specificity of receptor binding by vascular endothelial growth factor-d is different in mouse and man. J Biol Chem $\underline{276}, 19166-$ 19171.

Baldwin ME, Halford MM, Roufail S, Williams RA, Hibbs ML, Grail D, Kubo H, Stacker SA, Achen MG (2005): Vascular endothelial growth factor D is dispensable for development of the lymphatic system. Mol Cell Biol 25, 2441-2449.

Baluk P, Tammela T, Ator E, Lyubynska N, Achen MG, Hicklin DJ, Jeltsch M, Petrova TV, Pytowski B, Stacker SA, et al. (2005): Pathogenesis of persistant lymphatic vessel hyperplasia in chronic airway inflammation. J Clin Invest 115(2), 247-257

Banerji S, Ni J, Wang SX, Clasper S, Su J, Tammi R, Jones M, Jackson DG (1999): Lyve-1, a new homologue of the CD44 glycoprotein, is a lymph-specific receptor for hyaluronan. J Cell Biol $\underline{144}, 789-801$

Benzonana G, Skalli O, Gabbani G (1988): Correlation between the distribution of smoothmuscle and non-smooth muscle myosins and R-smooth muscle actin in normal and pathologic soft tissues; Cell Motil Cytoskeleton 11, 260 - 274 
Berse B, Brown LF, van de Water L, Dvorak HF, Senger DR (1992): Vascular permeability factor (vascular endothelial growth factor) gene is expressed differentially in normal tissues, macrophages, and tumors. Mol Biol Cell $\underline{3}, 211-220$

Biewenga J, Ende van der MB, Krist LFG, Borst A, Ghufron M, Rooijen van N (1995) Macrophage depletion in rat after intraperitoneal administration of liposome-encapsulated clodronate: depletion kinetics and acceleration repopulation of peritoneal and omental macrophages by administration of Freund's adjuvant. Cell Tissue Res 280, 189-196

Bill AH Jr, Sumner DS (1965): A unified concept of lymphangioma and cystic hygroma. Surg Gynecol Obstet $\underline{120}, 79-86$

Borek F: Adjuvants; in: (Sela M, eds.) The Antigens. Academic Press, New York 1977, 370-420

Bos HJ, Bronswijk H, Helmerhorst van TJM, Oe PL, Hoefmit ECM, Beelen RHJ (1988) Distinct subpopulations of elecited human macrophages in peritoneal dialysis patients and women undergoing laparoscopy: a study on peroxidatic activity. J Leukocyte Biol $\underline{43}, 172-178$

Broderson JR (1989): A retrospective review of lesions associated with the use of Freund's adjuvant. Lab Ani Sci 39, 400- 405

Cao Y, Linden P, Farnebo J, Cao R, Eriksson A, Kumar V, Qi JH, Claesson WL, Alitalo K (1998): Vascular endothelial growth factor C induces angiogenesis in vivo. Proc Natl Acad Sci USA $\underline{95}, 14389-14394$

Charabi B, Bretlau P, Bille M, Holmelund M (2000): Cystic hygroma of the head and neck - a long-term follow-up of 44 cases. Acta Otolaryngol Suppl $\underline{543}$, 248-250

Clark ER, Clark EL (1932): Observations on the new growth of lymphatic vessels as seen in transparent chambers introduced into the rabbit's ear. Am J Anat $\underline{51}, 49-87$

Cursiefen C, Chen L, Borges LP, Jackson D, Cao J, Radziejewski C, Amore PAD, Dana MR, Wiegand SJ, Streilein JW (2004): VEGF-A stimulates lymphangiogenesis and hemangiogenesis in inflammatory neovascularization via macrophage recruitment. J Clin Invest $\underline{113}$, 1040-1050

Dalchau R, Kirkley J, Fabre JW (1980): Monoclonal antibody to a human leukocyte-specific membrane glycoprotein probably homologous to the leukocyte-common (L-C) antigen of the rat. Eur J Immunol 10, 737-744

Dale MM (1960) The effects of Freund's adjuvanty on lymphatics in the mouse's ear. Br J Exp Pathol 41, 86-89

Dale MM (1961) The effects of the components of adjuvant emulsions on lymphatics in the mouse's ear. Br J Exp Pathol 42, 297-302

Deams WT, Brederoo P (1973) Electronmicroscopical studies on the structure, phagocytic properties and peroxidatic activity of resident and exsudate peritoneal macrophages in the guinea pig. Z Zellforsch $144,247-297$

Deams WT, Koerten HK (1978) The effects of various stimuli on the cellular composition of peritoneal exsudates in the mouse. Cell Tiss Res $\underline{190}, 47-60$ 
Deams WT, Wisse E, Brederoo P, Emeis JJ: Peroxidatic activity in monocytes and macrophages; in: (van Furth R, ed.) Mononuclear phagocytes in immunity, infection, and pathology. Blackwell Science Publ, Oxford 1975, 57-77

Deams WT, Koerten HK, Soranzo MR: Differences between monocyte-derived and tissue macrophages; in: (Reichard SM, Escobar MR, Friedman H, eds.) The reticulo-endothelial system in health and disease: Functions and characteristics. Plenum Press, New York-London 1976,2740

Delemarre FGA, Kors N, Kraal G, Rooijen van N (1990): Repopulation of macrophages in popliteal lymph nodes of mice after liposome mediated depletion. J Leukoc Biol 4ㄱ, 251-257

Engelhardt B, Conley FK, Butcher EC (1994): Cell adhesion molecules on vessels during inflammation in the mouse central nervous system. J Neuroimmunol $\underline{51}, 199-208$

Ezaki T, Kuwahara K, Morikawa S, Matsuno K, Sakaguchi N (2004): Characterization of adjuvant-induced rat lymphangiomas as a model to study the lymph drainage from abdominal cavity. Jpn J Lymphol 27, 1-10

Ezaki T, Kuwahara K, Morikawa S, Shimizu K, Sakaguchi N, Matsushima K, Matsuno K (2006): Production of two novel monoclonal antibodies that distinguish mouse lymphatic and blood vascular endothelial cells. Anat Embryol (Berl) 211, 379-393

Fageeh N, Manoukian J, Tewfik T, Schloss M, Williams HB, Gaskin D (1997): Management of head and neck lymphatic malformations in children. J Otolaryngol 26, 253-258

Fava RA, Olsen NJ, Spencer- Green G, Yeo KT, Yeo TK, Berse B, Jackman RW, Dvorak HF, Brown LF (1994): Vascular permeability factor/endothelial growth factor (VPF/VEGF): accumulation and expression in human synovial fluids and rheumatoid synovial tissue. J Exp Med $\underline{180}, 341-346$

Folkman J (1995): Angiogenesis in cancer, vascular rheumatoid and other disease. Nat Med $\underline{1}, 27-$ 31

Freund J (1951): The effect of paraffin oil and mycobacteria on antibody formation and sensitization; a review. Am J Clin Pathol 21, 645-656

Freund J, Thomson KJ, Hough HB, Sommer HE, Pisani TM (1948): Antibody formation and sensitization with the aid of adjuvants J Immunol $\underline{60}$, 383-398

Frigoletto FD Jr, Birnholz JC, Driscoll SG, Finberg HJ (1980): Ultrasound diagnosis of cystic hygroma. Am J Obstet Gynecol 136, 962-964

Furth R van (1976): Origin and kinetics of mononuclear phagocytes. Ann N Y Acad Sci 278, 161175

Furth R van, Cohn ZA (1968): The origin and kinetics of mononuclear phagocytes. J Exp Med $\underline{128}, 415-435$

Giguere CM, Bauman NM, Smith RJ (2002a): New treatment options for lymphangioma in infants and children. Ann Otol Rhinol Laryngol 111, 1066-1075 
Giguere CM, Bauman NM, Sato Y, Burke DK, Greinwald JH, Pransky S, Kelley P, Georgeson K, Smith RJH (2002b): Treatment of lymphangiomas with OK-432 (Picibanil) sclerotherapy. Arch Otolaryngol Head Neck Surg $\underline{128}, 1137-1144$

Goetsch E (1938): Hygroma colli cysticum and hygroma axillare: Pathologic and clinical study and report of twelve cases. Arch Surg $\underline{36}$, 394-479

Greinwald JH Jr, Burke DK, Sato Y, Poust RI, Kimura K, Bauman NM, Smith RJ (1999): Treatment of lymphangioma in children: an update of Picibanil (OK-432) sclerotherapie. Otolaryngol Head Neck Surg 121(4), 381-387

Hamoir M, Plouin-Gaudon I, Rombaux P, Francois G, Cornu AS, Desuter G, Clapuyt P, Debauche C, Verellen G, Beguin C (2001): Lymphatic malformations of the head and neck: a retrospective review and a support for staging. Head Neck $\underline{23}$, 326-337

Hermiston ML, Xu Z, Weiss A (2003): CD45: A critical regulator od signaling thresholds in immune cells. Annu Rev Immunol 21, 107-137

Hirakawa S, Hong YK, Harvey N, Schacht V, Matsuda K, Libermann T, Detmar M (2003): Identification of vascular lineagespecific genes by transcriptional profiling of insolated blood vascular and lymphatic endothelial cells. Am J Pathol 162, 575-586

Hoessli DC, Vassalli P (1980): High molecular weigt surface glycoproteins of murine lymphocytes. J Immunol $\underline{125}, 1758-1763$

Hong YK, Harvey N, Noh YH, Schacht V, Hirakawa S, Dermar M, Oliver G (2002): Prox1 is a master control gene in the program specifying lymphatic endothelial cell fate. Dev Dyn $225,351-$ 357

Hong YK, Lange-Asschenfeldt B, Velasco P, Hirakawa S, Kunstfeld R, Brown LF, Bohlen P, Senger DR, Detmar M (2004): VEGF-A promotes tissue repair-associated lymphatic vessel formation via VEGFR-2 and the a1b1 and a2b1 integrins. FASEB J 18, 1111-1113

Humphrey JH, White RG: Immunology for Students of Medicine. FA Davis Company, Philadelphia 1964

Jackson DG, Prevo R, Clasper S, Banerji S (2001): Lyve-1, the lymphatic system and tumor lymphangiogenesis. Trends Immunol 22, 317-321

Janz S, Herzschuh R, Storch H (1987): Evidence for high purity of commercial pristine (2,6,10,14-tetramethylpentane) preparation used for plasmocytoma induction in BALB/c mice. Exp Pathol 31(4), 253-255

Jeltsch M, Kaipainen A, Joukov V, Meng X, Lakso M, Rauvala H, Swartz M, Fukumura D, Jain RK, Alitalo K (1997): Hyperplasia of lymphatic vessels in VEGF-C transgenic mice. Science 276(5317), 1423-1425

Joukov V, Pajusola K, Kaipainen A, Chilov D, Lahtinen I, Kukk E, Saksela O, Kalkkinen N, Alitalo K (1996): Anovel vascular endothelial growth factor, VEGF-C, is a ligand for the Flt4 (VEGFR-3 and KDR (VEGFR-2) receptor tytosine kinases. EMBO J 15(2), 290-298 
Joukov V, Sorsa T, Kumar V, Jeltsch M, Claesson -Welsh L, Cao Y, Saksela O, Kalkkinen N, Alitalo K (1997): Proteolytic processing regulates receptor specificity and activity of VEGF-C. EMBO J 16, 3898-3911

Kaipainen A, Korhonen J, Mustonen T, van Hinsbergh VW, Fang GH, Dumont D, Breitman M, Alitalo K (1995): Expression of the fms-like tyrosine kinase 4 gene becomes restricted to lymphatic endothelium during developement. Proc Natl Acad Sic 92, 3566-3570

Kasten P, Schnöink G, Bergmann A, Papoutsi M, Buttler K, Rössler J, Weich HA, Wilting J (2007): Similarities and Differences of Human and Experimental Mouse Lymphangiomas. Dev Dyn 236, 2952-2961

Koch AE, Polverini PJ, Leibovich JL (1986): Induction of neovasculanzation by activated human monocytes. J Leuk Biol $\underline{39}$, 233-238

Koch BL (2005): Cystic malformations of the neck in children. Pediatr Radiol 35, 463-477

Kriehuber E, Breiteneder-Geleff S, Groeger M, Soleimann A, Schoppmann SF, Stingl G, Kerjaschki D, Maurer D (2001): Isolation and characterization of dermal lymphatic and blood endothelial cells reveal stable and functionally specialized cell lineages. J Exp Med 194 (6), 797808

Kubo H, Fujiwara T, Jussila L, Hashi H, Ogawa M, Shimizu K, Awane M, Sakai Y, Takabayashi A, Alitalo K, Yamaoka Y, Nishikawa SI (2000): Involvement of vascular endothelial growth factor receptor-3 in maintenance of integrity of endothelial cell lining during tumor angiogenesis. Blood 무, 546-553

Kubo H, Cao R, Brakenhielm E, Makinen T, Cao Y, Alitalo K (2002): Blockade of vascular endothelial growth factor receptor-3 signaling inhibits fibroblast growth factor-2-induced lymphangiogenesis in mouse cornea. Proc Natl Acad Sci USA 99(13), 8868-8873

Landing BH, Faber S: Tumors of the cardiovascular System; in: Atlas of Tumor Pathology, Section III, Fascicle 7., Armed Forces Institute of Pathology, Washington, DC, 1956, 124-138

Lee BB, Kim YW, Seo JM, Hwang JH, Do YS, Kim DI, Byun HS, Lee SK, Huh SH, Hyun WS (2005): Current concepts in lymphatic malformations. Vasc Endovasc Surg ⒐ 67-81

Lee J, Gray A, Yuan J, Luoh SM, Avraham H, Wood WI (1996): Vascular endothelial growth factor-related protein: a ligand and specific activator of the tyrosine kinase receptor Flt4. Proc Natl Acad Sci USA 무, 1988-1992

Lee K, Klein TR: Surgery of cysts and tumors of the neck; in: Otolaryngology, Paparella M, Shunrick D (eds). WB Saunders, Philadelphia, PA, 1980, 2988-2989

Makinen T, Veikkola T, Mustjoki S, Karpanen T, Catimel B, Nice EC, Wise L, Mercer A, Kowalski H, Kerjaschki D, Stacker SA, Achen MG, Alitalo K (2001a): Isolated lymphatic endothelial cells transduce growth, survival and migratory signals via the VEGF-C/D receptor VEGFR-3. EMBO J 20(17), 4762-4773 
Makinen T, Jussila L, Veikkola T, Karpanen T, Kettunen MI, Pulkkanen KJ, Kauppinen R, Jackson DG, Kubo H, Nishikawa S, et al. (2001b): Inhibition of lymphangiogenesis with resulting lymphedema in transgenic mice expressing soluble VEGF receptor-3. Nat Med $\underline{7}, 199-205$

Mancardi S, Stanta G, Dusetti N, Bestagno M, Jussila L, Zweyer M, Lunazzi G, Dumont D, Alitalo K, Burrone OR (1999): Lymphatic endothelial tumors inducted by intraperitoneal injection of incomplete Freund's adjuvant. Exp Cell Res 264, 363-375

McDonald AH, Degrassi A (1993): Pristane induces an indomethacin inhibitable inflammatory influx of CD4+ T cells and IFN-gamma production in plasmacytoma-susceptible BALB/cAnPt mice. Cell Immunol 146, 157-170

Merrill W, Chase D (1976): Developements in delayed-type hypersensitivities: 1950-1975. J Inv Dematol 67, 136-148

Merwin RH, Redmon LW (1963): Induction of plasma cell tumors and sarcomas in mice by diffusion chambers placed in the peritoneal cavity. J Nat Cancer Inst $\underline{31}$, 998-1017

Müller WA, Ratti CM, McDonnell SL, Cohn ZA (1989): A human endothelial cell-restricted, externally disposed plasmalemmals protein enriched in intercellular junctions. J Exp Med 170, 399-414

Nagy JA, Vasile E, Feng D, Sundberg C, Brown LF, Detmar MJ, Lawitts JA, Benjamin L, Tan X, Manseau EJ, Dvorak AM, Dvorak HF (2002): Vascular permeability factor/vascular endothelial growth factor induces lymphangiogenesis as well as angiogenesis. J Exp Med 196 (11), 1497-1506

Nussinovitch M, Grozovski S, Volovitz B, Amir J (2001): Infected Congenital Cystic Hygroma. IMAJ $\underline{3}, 545$

Ogita S, Tsuto T, Nakamura K, Deguchi E, Iwain N (1994): OK-432 therapy in 64 patients with lymphangioma. J Pediatr Surg 29(6), 784-785

Oh SJ, Jeltsch MM, Birkenhäger R, McCarthy JE, Weich HA, Christ B, Alitalo K, Wilting J (1997): VEGF and VEGF-C: specific induction of angiogenesis and lymphangiogenesis in the differentiated avian chorioallantoic membrane. Dev Biol 188, 96-109

Orlandini M, Marconcini L, Ferruzzi R, Oliviero S (1996) Identification of a c-fos inducted gene that is related to the platelet-derived growth factor / vascular endothelial growth factor family. Proc Natl Acad Sci USA 르, 11675-11680

Orvidas LJ, Kasperbauer JL (2000): Pediatric lymphangiomas of the head and neck. Ann Otol Rhinol Laryngol 109, 411-421

Papoutsi M, Siemeister G, Weindel K, Tomarev SI, Kurz H, Schächtele C, Martiny-Baron G, Christ B, Marme D, Wilting J (2000): Active interaction of human A375 melanoma cells with the lymphatics in vivo. Histochem Cell Biol $\underline{114}$, 373-385

Partanen TA, Alitalo K, Miettinen M (1999): Lack of lymphatic vascular specificity of vascular endothelial growth factor receptor-3 in 185 vascular tumors. Cancer $\underline{86}$ (11), 2406-2412 
Partanen TA, Arola J, Saaristo A, Jussila L, Ora A, Miettinen M, Stacker SA, Achen MG, Alitalo $\mathrm{K}$ (2000): VEGF-C and VEGF-D expression in neuroendocrine cells ans their receptor, VEGFR-3 in fenestrated blood vessels in human tissues. FASEB J 14, 2087-2096

Perkes EA, Haller JO, Kassner EG, Wolf E, Velcek FD (1979): Mediastinal cystic hygroma in infants. Clin Pediatr 18, 168-170

Petrova TV, Makinen T, Makela TP, Saarela J, Virtanen I, Ferrell RE, Finegold DN, Kerjaschki D, Yla-Herttuala S, Alitalo K (2002): Lymphatic endothelial reprogramming of vascular endothelial cells by Prox-1 homeobox transcription factor. EMBO J 21, 4593-4599

Philips H, McGahan J (1981): Intauterine fetal cystic hygromata: sonographic detection. AJR $\underline{136}$, 799-802

Plasman N, Vray B (1993): Mouse peritoneal macrophages: characterization of functional subsets following Percoll density gradients. Res Immunol 144, 151-163

Potter EL, Craig JM: Pathology of the fetus and the infant. (ed 3). Chicago: Year Book, 1975

Potter M (1972): Immunglobulin-producing tumors and myeloma proteins of mice. Physiol Rev $\underline{52}, 631-719$

Potter M, Robertson CL (1960): Developement of plasma-cell neoplasms in BALB/c mice after intraperitoneal injektion of paraffin-oil adjuvant, heat-killed Staphylococcus mixtures. J Nat Cancer Inst 25, 847-861

Potter M, Boyce CR (1962): Induction of plasmacell neoplasms in stain BALB/c mice with mineral oil and mineral oil adjuvants. Nature (London) $\underline{193}, 1086-1087$

Potter M, MacCardle RC (1964) Histology of developing plasma cell neoplasia induced by mineral oil in BALB/c mice. J Natl Cancer Inst $\underline{33}$, 497-515

Potter M, Wax JS, Anderson AO, Nordan RP (1985): Inhibition of plasmacytoma developement in BALB/c mice by indomethacin. J Exp Med 160, 996-1012

Prevo R, Banerji S, Ferguson DJP, Clasper S, Jackson DG (2001): Mouse Lyve-1 is an endocytic receptor for hyaluronan in lymphatic endothelium. J Biol Chem $\underline{276}$, 19420-19430

Pullinger BD, Florey HW (1937) Proliferation of lymphatics in inflammation. J Pathol Bacteriol $\underline{45}, 157-170$

Rodriguez-Niedenführ M, Papoutsi M, Christ B, Nicolaides KH, von Kaisenberg CS, Tomarev SI, Wilting J (2001): Prox1 is a marker of ectodermal placodes, endodermal compartments, lymphatic endothelium und lymphangioblasts. Anat Embryol 204, 399-406

Schacht V, Ramirez MI, Hong YK, Hirakawa S, Feng D, Harvey N, Williams M, Dvorak AM, Dvorak HF, Oliver G, Detmar M (2003): T1alpha/podoplanin deficiency disrups normal lymphatic vasculature formation and causes lymphedema. EMBO J 22, 3546-3556 
Schoppmann SF, Birner P, Stockl J, Kalt R, Ullrich R, Caucig C, Kriehuber E, Nagy K, Alitalo K Kerjaschki D (2002): Tumor associated macrophages express lymphatic endothelial growth factors and are related to peritumoral lymphangiogenesis. Am J Pathol 161(3), 947-956

Short RF, Shiels WE, Sferra TJ, Nicol KK, Schofield M, Wiet GJ (2007): Site-specific induction of lymphatic malformations in a rat model for image-guided therapy. Pediatr Radiol 37(6), 530534

Singh RP, Carr DH (1966): The anatomy and histology of XO human embryos and fetuses. Anat Rec 155, 369-383

Sironi M, Conti A, Bernasconi S, Fra AM, Pasqualini F, Nebuloni M, Lauri E, De Bortoli M, Mantovani A, Dejana E, Vecchi A (2006): Generation and characterization of a mouse lymphatic endothelial cell line. Cell Tissue Res $\underline{325}, 91-100$

Skalli O, Ropraz P, Trzeciak A, Benzonana G, Gillessen D, Gabani G (1986): A monoclonal antibody against R-smooth muscle actin: A new probe for smooth muscle differentiation; J Cell Biol 103, 2787- 2796

Skobe M, Detmar M (2000): Structure, function and molecular control of the skin lymphatic system. J Invest Dermatol Symp Proc $\underline{5}, 14-19$

Skobe M, Hamberg L, Hawighorst T, Schirner M, Wolf GL, Alitalo K, Detmar M (2001): Concurrent induction of lymphangiogenesis, angiogenesis, and macrophag recruitment by vascular endothelial growth factor-C in melanoma. Am J Pathol $\underline{159}$, 893-903

Slawa J (1980) Experimental plasmacytomas in mice. I. Induction, morphological and biological characteristics. Arch Immunol Ther Exp 28, 167-172

Smith D: Recognizable patterns of human malformations: Genetic, embryologic and clinical aspects. (ed 3). WB Saunders, Philadelphia, 1982, 72-473

Stacker SA, Stenvers K, Caesar C, Vitali A, Domagala T, Nice E, Roufail S, Simpson RJ, Moritz R, Karpanen T, Alitalo K, Achen MG (1999): Biosynthesis of vascular endothelial growth factor$\mathrm{D}$ involves proteolytic processing which generates non-covalent homodimers. J Biol Chem $\underline{274}$, 32127-32136

Standring R, McMaster WR, Sunderland CA, Williams AF (1978): The predominant heavily glycosylated glycoproteins at the surface of rat lymphoid cells are differentiation antigens. Eur J Immunol $\underline{8}, 832-839$

Sunderkotter C, Steinbrink K, Goebeler M, Bhardwaj R., Sorg C (1994): Macrophages and angiogenesis. J Leukoc Biol $\underline{55}$, 410-422

Sunderland CA, McMaster WR, Williams AF (1979): Purification with monoclonal antibody of a predominant leukocyte-common antigen and glycoprotein from rat thymocytes. Eur J Immunol $\underline{9}, 155-159$

Taichman NS, Young S, Cruchley AT, Taylor P, Paleolog E (1997): Human neutrophils secrete vascular endothelial growth factor. J Leukoc Biol $\underline{62}$, 397-400 
Takakura K, Mason WB, Hollander VP (1966): Studies on the Pahogenesis of plasma call tumors. I. Effect of cortisol on developement of plasma cell tumors. Cancer Res 26 (1), 596-599

Thomas ML (1989): The leukocyte common antigen family. Ann Rev Immunol 포 339-369

Trowbridge IS (1978): Interspecies spleen-myeloma hybrid producting monoclonal antibodies against mouse lymphocyte surface glycoprotein, T200. J Exp Med 148, 313-323

Trowbridge IS, Thomas ML (1994): CD45: an emerging role as a protein tyrosine phosphatase required for lymphocyte activation and development. Annu Rev Immunol 12, 85-116

Veikkola T, Jussila L, Makinen T, Karpanen T, Jeltsch M, Petrova TV, Kubo H, Thurston G, McDonald DM, Achen MG, Stacker SA, Alitalo K (2001): Signalling via vascular endothelial growth factor receptor-3 is sufficient for lymphangiogenesis in transgenic mice. EMBO J $\underline{20}$, 1223-1231

Wetterwald A, Hoffstetter W, Cecchini MG, Lanske B, Wagner, Fleisch H, Atkinson M (1996): Characterization and cloning of the E11 antigen, a maker expressed by rat osteoblasts and osteocytes. Bone $\underline{18}, 125-132$

Wigle JT, Oliver G (1999): Prox1 function is required for the developement of the murine lymphatic system. Cell $\underline{98}, 769-778$

Wigle JT, Harvey N, Detmar M, Lagutina I, Grosveld G, Gunn MD, Jackson DG, Oliver G (2002): An essential role for Prox1 in the induction of the lymphatic endothelial cell phenotype. EMBO J 21, 1505-1513

Wilting J, Eichmann A, Christ B (1997): Expression of the avian VEGF receptor homologues Quek1 and Quek2 in blood-vascular and lymphatic endothelial and non-endothelial cells during quail embryonic developement. Cell Tissue Res 288, 207-223

Wilting J, Papoutsi M, Christ B, Nicolaides KH, von Kaisenberg CS, Borges J, Stark GB, Alitalo K, Tomarev SI, Niemeyer C, Rossler J (2002): The transcription factor Prox1 is a marker for lymphatic endothelial cells in normal and diseased human tissues. FASEB J 16, 1271-1273

Yamada H, Mashburn LT, Takakura K, Hollander VP (1969): The correlation between plasma cell tumor developement and antibody response in inbred stains of mice. Proc Soc Exp Biol Med $\underline{131}, 947-950$

Yamada Y, Nezu J, Shimane M, Hirata Y (1997): Molecular cloning of a novel vascular endothelial growth factor VEGF-D. Genomics $\underline{42}$, 483-488

Zadvinskis DP, Benson MT, Kerr HH, Mancuso AA, Cacciarelli AA, Madrazo BL, Mafee MF, Dalen K (1992): Congenital malformations of the cervicothoracic lymphatic system: Embryology and Pathogenesis. Radio Graphics 12, 1175-1189 


\section{Abkürzungsverzeichnis}

Alpha-SMA

BSA

CD31

CD45

FIA

KPP

Lyve1

Meca32

Prox1

VEGFR- 2

VEGFR- 3
Alpha- Smooth-Muscle-Actin

Bovines Serumalbumin

Cluster of Differentiation Molecule 31

Cluster of Differentiation Molecule 45

Freund's Incomplete Adjuvant

Kaliumphosphatpuffer

Lymphatic Vascular Endothelial Hyaluron Receptor-1

Mouse endothelial cell antigen 32

Prospero-related Homeoboxgen-1

Vascular Endothelial Growth Factor Receptor- 2

Vascular Endothelial Growth Factor Receptor- 3 


\section{Danksagung}

Mein besonderer Dank gilt meinem Doktorvater, Herrn Prof. Dr. rer. nat. J. Wilting, für die Überlassung des interessanten Promotionsthemas und die hervorragende Betreuung während der gesamten Bearbeitung. In diversen Erörterungen und Diskussionen vermochte er mir wertvolle Anregungen zu geben, die zum Gelingen dieser Promotionsschrift beigetragen haben.

Bedanken möchte ich mich an dieser Stelle auch bei Herrn Dr. H.A. Weich (HZI in

Braunschweig) für die hervorragende Kooperation bei der Herstellung der Lymphangiom-

Präparate. Großer Dank gilt auch Frau Dr. K. Buttler und Frau Dr. M. Papoutsi, die mir beide bei Fragen und Problemen stets hilfsbereit zur Seite gestanden haben, sowie Frau M. Böning für die Einarbeitung in die Immunhistologie und die gute Zusammenarbeit im Labor. 


\section{Lebenslauf}

Ich wurde am 08.10.1981 in Bremen geboren. 1988 wurde ich an der Käthe-Kollwitz-

Grundschule in Delmenhorst eingeschult. 1992-1994 besuchte ich das Pestalozzi-Schulzentrum, Delmenhorst, um im Sommer 1994 zum Gymnasium an der Max-Planck-Straße, Delmenhorst, zu wechseln, wo ich 2001 die Allgemeine Hochschulreife erlangte. Im Herbst 2001 begann ich ein Psychologiestudium an der Christian-Albrechts-Universität Kiel, das ich schon bald abbrach, um im Frühjahr 2003 an der Georg-August-Universität, Göttingen Medizin zu studieren. Im März 2005 legte ich die ärztliche Vorprüfung (Physikum) ab und am 16.06. 2009 habe ich den zweiten Abschnitt der ärztlichen Prüfung bestanden.

Gerrit Sebastian Schnöink 